\title{
Fast Hybrid MPPT Technique for Photovoltaic Applications: Numerical and Experimental Validation
}

\author{
Gianluca Aurilio, ${ }^{1}$ Marco Balato, ${ }^{1}$ Giorgio Graditi, ${ }^{2}$ Carmine Landi, ${ }^{1}$ \\ Mario Luiso, ${ }^{1}$ and Massimo Vitelli ${ }^{1}$ \\ ${ }^{1}$ Department of Industrial and Information Engineering, Second University of Naples, Via Roma 29, 81031 Aversa, Italy \\ ${ }^{2}$ ENEA Portici Research Centre, P. E. Fermi 1, Naples, 80055 Portici, Italy \\ Correspondence should be addressed to Mario Luiso; mario.luiso@unina2.it
}

Received 14 January 2014; Revised 31 March 2014; Accepted 22 April 2014; Published 3 June 2014

Academic Editor: Pavol Bauer

Copyright (C) 2014 Gianluca Aurilio et al. This is an open access article distributed under the Creative Commons Attribution License, which permits unrestricted use, distribution, and reproduction in any medium, provided the original work is properly cited.

In PV applications, under mismatching conditions, it is necessary to adopt a maximum power point tracking (MPPT) technique which is able to regulate not only the voltages of the PV modules of the array but also the DC input voltage of the inverter. Such a technique can be considered a hybrid MPPT (HMPPT) technique since it is neither only distributed on the PV modules of the PV array or only centralized at the input of the inverter. In this paper a new HMPPT technique is presented and discussed. Its main advantages are the high MPPT efficiency and the high speed of tracking which are obtained by means of a fast estimate of the optimal values of PV modules voltages and of the input inverter voltage. The new HMPPT technique is compared with simple HMPPT techniques based on the scan of the power versus voltage inverter input characteristic. The theoretical analysis and the results of numerical simulations are widely discussed. Moreover, a laboratory test system, equipped with PV emulators, has been realized and used in order to experimentally validate the proposed technique.

\section{Introduction}

In PV applications, the maximum power point (MPP) of the power versus voltage $(P-V) \mathrm{PV}$ characteristic must be continuously tracked in order to extract the maximum energy. Many MPP tracking (MPPT) techniques have been presented in the literature [1-4]. Mismatch operating conditions of the PV modules are due to clouds, shadows of neighboring objects, dirtiness, manufacturing tolerances, different orientation of parts of the PV field, dust, aging, and so forth. In case of mismatch, the $P-V$ characteristic of the PV field may exhibit more peaks, due to the presence of bypass diodes. In such conditions, MPPT algorithms can fail causing a marked reduction of the overall system efficiency [1-4]. Moreover, the global maximum power of the mismatched PV field is lower than the sum of the available maximum powers that the mismatched modules would be able to provide if each of them could operate in its own MPP. In order to allow each PV module of the array to provide its own maximum power, it is possible to use module-dedicated DC/AC converters (microinverters) $[5,6]$ or module-dedicated DC/DC converters (microconverters) and central inverters [7-25]. The module-dedicated converters carry out the MPPT on each PV module. In this paper, the attention is focused on PV applications adopting module-dedicated DC/DC converters and central inverters. A not exhaustive list of commercial MPPT DC/DC converters (often called microconverters or power optimizers) includes SolarMagic power optimizers by National Semiconductors (four-switch buck-boost topology) [26], SolarEdge power box (buck-boost topology) [27], Tigo Energy Module Maximizers (MM-ES50, MM-ES75, MMES110, MM-ES170, buck topology) [28], Xandex SunMizers (buck topology) [29], SPV1020 produced by STMicroelectronics (boost topology) [30], eIQ Energy Vboost (boost topology) [28], and Tigo Energy power optimizers (MMEP35, MM-EP45, MM-EP60 (boost topology)) [28]. Therefore, commercial power optimizers based on the buck, or on the boost or on the buck-boost topology, are available. In [20], 
the buck, the boost, the Cuk, and the buck-boost topologies are considered as possible microconverters. Advantages and drawbacks of such topologies are examined in detail, and the conclusion is that, although more flexible in voltage ranges, buck-boost and Cuk topologies are characterized by lower efficiencies and higher costs because of enhanced component stresses. In [21], such a result has been confirmed by using the tool represented by the so-called "feasibility region." In particular, in [21], it is shown that, in correspondence with the same conditions as concerns irradiance and temperature operating values and voltage and current ratings of the adopted devices, buck-boost converters are characterized by feasibility regions that are smaller than the corresponding ones of boost converters. Therefore, much more frequently with respect to the case of the boost converters, buck-boost "feasibility regions" do not include the global MPP of the PV system. In other words, if components (MOSFETS, diodes, capacitors, etc.) characterized by the same voltage and current ratings are adopted, boost converters are more suitable than buck-boost converters for DMPPT PV applications since they exhibit not only higher power stage efficiencies, but also higher DMPPT efficiencies.

As for the buck converter, it optimally works especially in PV systems with limited mismatch, for example, where shade or mismatch occurs only on a few PV panels. In this case, the buck DC/DC converter can be installed only on those PV panels experiencing shade [22]. The adoption of buck converters on all the PV modules of the string is unpractical, because of the associated step-down voltage conversion ratio, since it leads of course to a more or less consistent increase of the number of modules for each string to obtain a string voltage compatible with the input voltage range of the inverter.

On the basis of the aforementioned considerations, if a reasonable, fair comparison among topologies is carried out, by taking into account power stage efficiency, cost, voltage, and current stress of components and therefore their duration in service, it can be concluded that a practical compromise solution for series-connected DC/DC converters installed on all the PV modules of the string is generally represented just by the boost converter.

Therefore, in the following, DMPPT PV systems based on the adoption of boost DC/DC converters will be considered (Figure 1). In the sequel, a system composed of a PV module equipped with a dedicated DC/DC MPPT converter will be called self-controlled PV module (SCPVM). Moreover, the term central MPPT (CMPPT) will be used with reference to a MPPT technique which regulates the output voltage of a whole array of SCPVMs and which is carried out by the central controller equipping the inverter. Instead, the term distributed MPPT (DMPPT) will be used with reference to a MPPT technique which simultaneously regulates the output voltage of each PV module. The DMPPT technique is simultaneously carried out by all the controllers equipping the DC/DC converters of the array of SCPVMs. In $[31,32]$, the reasons why the joint adoption of both CMPPT and DMPPT techniques is necessary are discussed in detail. Basically, in $[31,32]$, it is shown that, in order to obtain full profit from DMPPT, it is necessary that the bulk inverter voltage

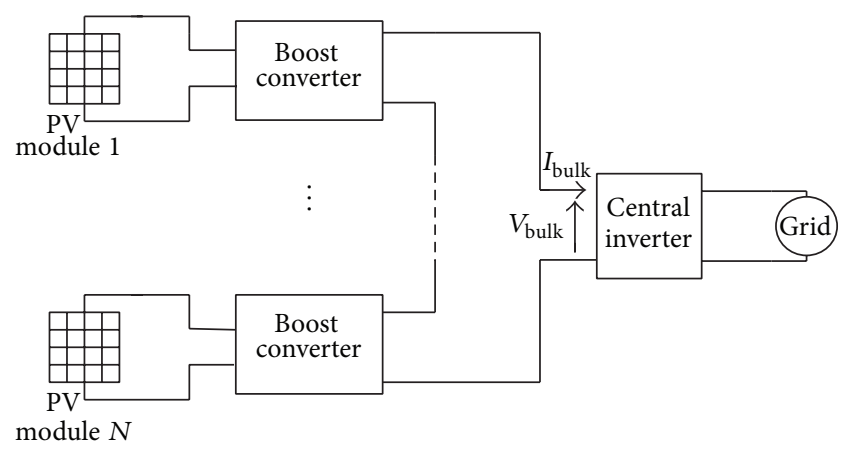

FIGURE 1: Grid-connected PV system with microconverters.

belongs to an optimal range whose position and amplitude depend on the number of SCPVMs in the string, on the atmospheric operating conditions characterizing each PV module (irradiance and temperature values), on the voltage and current ratings of the physical devices the power stages of SCPVMs are made of, and on the adopted DC/DC converter topology. In the following, the control technique based on the joint adoption of DMPPT and CMPPT techniques will be denoted with the acronym HMPPT (hybrid MPPT).

In [31,32], it has been clarified that, in order to avoid that the PV system operating point remains trapped in the proximity of a suboptimal point, thus wasting the presence of the microconverters, the CMPPT technique cannot be based on the perturb and observe ( $\mathrm{P} \& \mathrm{O})$ technique as well as on any other standard MPPT technique. Instead, it is possible to adopt a technique based on the scan of the $P-V$ characteristic of the array of SCPVMs [33]. The HMPPT technique based on the coupled adoption of the P\&O DMPPT technique and the CMPPT technique using the scan of the $P-V$ characteristic of the string of SCPVMs will be called HMPPT_S technique. Another possible HMPPT technique is based on a strategy in which the CMPPT and the DMPPT techniques exploit an algorithm aimed at evaluating a proper starting set of voltage reference values for the PV modules and the inverter [34]. Such values are quite near to the actual optimal ones so that their eventual, subsequent refinement process can be very fast. The above algorithm, which is based on the fast estimate of the maximum power voltages, will be indicated with the acronym FEMPV [34, 35]. The HMPPT technique based on the adoption of the FEMPV algorithm will be called HMPPT_F. A PV system controlled with the HMPPT_F technique is shown in Figure 2 where the presence of the DMPPT and of the CMPPT controllers is put in evidence. Moreover, in Figure 2, the exchange of data among the CMPPT and the DMPPT controllers is also put in evidence. Such a feature will be explained in detail as follows. In the sequel, without loss of generality, we will refer to a system composed of N lossless SCPVMs based on the boost topology. The term "lossless" is adopted not only because losses taking place in the power stage of the boost converters (conduction losses, switching losses, iron losses, etc.) or in connecting cables are neglected, but also because it will be assumed that the MPPT efficiency is equal to one. 


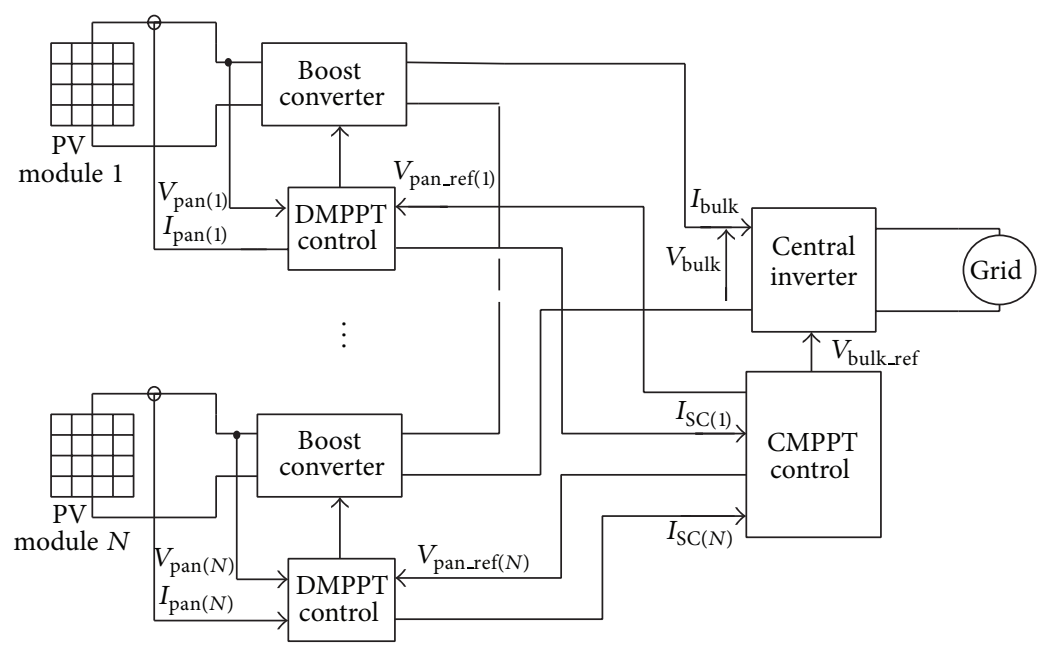

FIGURE 2: Grid-connected PV system adopting the HMPPT_F technique.

In Section 2, the working principle of the FEMPV algorithm is explained. Section 3 discusses the results of numerical simulations and Section 4 focuses on the implementation of a test system for the laboratory characterization of the presented technique. Finally, Section 5 shows the experimental results.

\section{Working Principle of the FEMPV Algorithm}

In this section, the HMPPT_F technique will be described in detail. Such a technique is based on the estimate of the optimal operating range $R_{b}$ of the inverter input voltage and on the estimate of the optimal operating voltages $V_{\text {pan_ref }}(k)$ $(k=1,2, \ldots, N)$ of the PV modules. As it will be shown in the following, in order to get enough accurate information concerning $R_{b}$ and $V_{\text {pan_ref }}(k)$, it is not necessary to deal with the exact $I-V$ characteristics of the SCPVMs but a proper approximate version of such characteristics is enough. This section is devoted to the identification of the guidelines to follow in order to obtain such an approximate version. In the following, without loss of generality, SolarWorld SW225 PV modules will be considered, in order to carry out numerical simulations. Their characteristic parameters in STC (that is $\mathrm{AM}=1.5$, irradiance value $S=1000 \mathrm{~W} / \mathrm{m}^{2}$, and module temperature $T_{\text {module }}=25^{\circ} \mathrm{C}$ ) are open circuit voltage $V_{\text {oc }}=$ $36.8 \mathrm{~V}$, short circuit current $I_{\mathrm{SC}}=8.17 \mathrm{~A}$, MPP voltage $V_{\mathrm{MPP}}$ $=29.5 \mathrm{~V}, \mathrm{MPP}$ current $I_{\mathrm{MPP}}=7.63 \mathrm{~A}$, and nominal operating cell temperature NOCT $=46^{\circ} \mathrm{C}$.

The approximated $I-V$ SCPVM characteristic is obtained like shown in Figure $3[34,35]$ :

$$
\begin{gathered}
I=I_{\text {cost }}=\beta \cdot I_{\mathrm{SC}}, \quad V \leq V_{\mathrm{MPP}}, \\
I=V_{\mathrm{MPP}} \cdot \frac{I_{\text {cost }}}{V}, \quad V_{\mathrm{MPP}} \leq V<V_{\mathrm{ds} \max }, \\
V_{\mathrm{MPP}} \cdot \frac{I_{\text {cost }}}{V_{\mathrm{ds} \max }} \leq I \leq 0, \quad V=V_{\mathrm{ds} \max },
\end{gathered}
$$

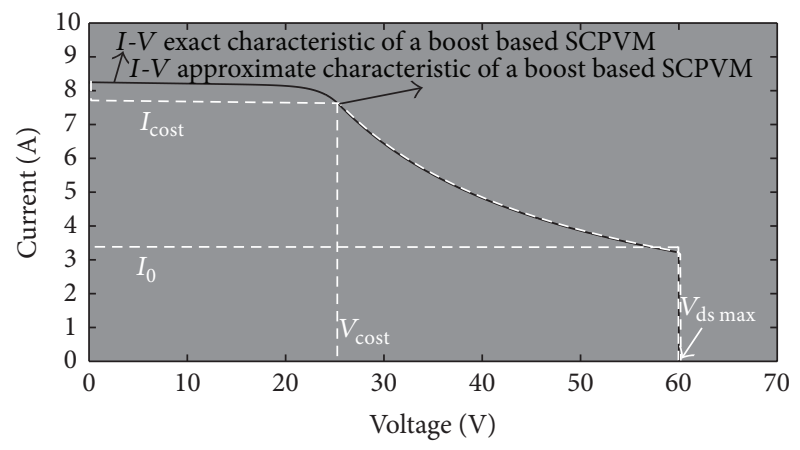

FIGURE 3: $I-V$ exact and approximated characteristics of a boost based SCPVM $\left(S=1000 \mathrm{~W} / \mathrm{m}^{2}, T_{\text {ambient }}=25^{\circ} \mathrm{C}, V_{\text {cost }}=26.24 \mathrm{~V}, I_{\text {cost }}\right.$ $=7.42 \mathrm{~A}$, and $\left.V_{\mathrm{ds} \max }=60 \mathrm{~V}\right)$.

where $I$ represents the output current and $V$ the output voltage of a SCPVM, $\beta$ is the ratio between $I_{\text {MPP_STC }}$ (MPP current in STC) and $I_{\text {SC_STC }}$ (short circuit current in STC), $V_{\mathrm{ds} \max }$ represents the maximum allowable voltage across the switches of the boost converter, and $V_{\text {MPP }}$ is the MPP voltage of the PV module. In the case of the SW225 modules, it is $\beta$ $=0.93$. The approximation of the $I-V$ characteristic can be justified by considering that the exact $I-V$ characteristic is more or less flat, for $V \leq V_{\mathrm{MPP}}$, and it is contained in the quite narrow band $I_{\mathrm{MPP}} \leq I \leq I_{\mathrm{SC}}$ (usually $I_{\mathrm{MPP}} / I_{\mathrm{SC}} \approx 0.9$ ). It is worth noting that of course other more accurate forms of approximation of the curve for $V \leq V_{\mathrm{MPP}}$ might be in principle used, for example, a piece-wise linear approximation. But, as it will be shown in the following, it is not necessary at all. In fact, the use of the simple approximation (1) allows easily carrying out in closed form, with enough accuracy, the calculations needed by the HMPPT_F technique in order to maximize the energetic efficiency of a PV system with microconverters. Indeed some additional considerations are needed concerning the values to adopt for $V_{\mathrm{MPP}}$. For a given PV module, $V_{\text {MPP }}$ is generally weakly dependent on the irradiance and on the module temperature $[32,36]$. Usually 
the variations of $V_{\text {MPP }}$ are relatively small. Therefore, due to the approximate nature of the analysis to be carried out, in the following, $V_{\text {MPP }}$ will be considered constant instead of timevarying. In particular, $V_{\text {MPP }}$ will be considered equal to the value $V_{\text {cost }}$ assumed by the MPP voltage at $S=1000 \mathrm{~W} / \mathrm{m}^{2}$ and $T_{\text {ambient }}=25^{\circ} \mathrm{C}$. In such conditions, by using (2), it is possible to evaluate the module temperature $T_{\text {module }}[36]$ :

$$
T_{\text {module }}=T_{\text {ambient }}+\left(\operatorname{NOCT}-20^{\circ}\right) * \frac{\mathrm{S}}{800} .
$$

With specific reference to SW225 modules, it is $T_{\text {module }}=$ $57.5^{\circ} \mathrm{C}$. Hence the desired value of $V_{\text {cost }}$ can be finally obtained $[32,36]$ :

$$
V_{\text {cost }}=V_{\text {MPP_STC }} \cdot\left[1+\alpha \cdot \frac{\left(T_{\text {module }}-25\right)}{100}\right],
$$

where $\alpha\left[\% /{ }^{\circ} \mathrm{K}\right]$ is a negative temperature coefficient (in the case of SW 225 modules, it is $\alpha=-0.34 \% /{ }^{\circ} \mathrm{K}$ and hence $V_{\text {cost }}$ $=26.24 \mathrm{~V}$ ).

It is worth noting that (2) is able to provide only a rough estimate of the module temperature as a function of the irradiance level and of the ambient temperature. Nevertheless, this is enough for the closed form approximate analysis which represents the subject of this paper. Of course, should a more accurate evaluation of the module temperature be needed, then, the main heat transfer mechanisms between the module and its surrounding environment should be precisely taken into account [37]. But this is not necessary since we explicitly remark here that the focus is on a simplified closed form approximate analysis which is able to provide suitable starting values for the DC inverter voltage and for the PV modules voltages. Such values can be successively refined by means of standard hill-climbing techniques in order to overcome the potential errors associated with the adopted approximations. Therefore, there is no need to complicate the analysis by including accurate thermal considerations while, at the same time, simplifying approximations are used elsewhere in the proposed algorithm.

It is worth noting that the parameters $V_{\text {MPP_STC }}$ and $\alpha$ appearing in (3) are provided by all the PV module manufacturers in their datasheets and $T_{\text {module }}$ has been easily evaluated by means of (2). Therefore all the parameters needed for the calculation of $V_{\text {cost }}$ are easily available. As shown in the following, despite the above approximations, the obtained results are enough accurate for our purposes. In Figure 3, the $I-V$ approximated characteristic of a boost based SCPVM and the exact characteristic are shown with reference to $S=1000 \mathrm{~W} / \mathrm{m}^{2}, T_{\text {ambient }}=25^{\circ} \mathrm{C}$, and $V_{\mathrm{ds} \max }=60 \mathrm{~V}$.

Let us define current $I_{0}$ :

$$
I_{0}=\frac{V_{\text {cost }} \cdot I_{\text {cost }}}{V_{\text {ds } \max }}<I_{\text {cost }} .
$$

The meaning of such a current, which is useful for the following analysis, is highlighted in Figure 3. In the following, it will be shown how the approximate equivalent $P-V$ characteristic of the string of SCPVMs can be evaluated once the approximate $I-V$ characteristics of all the N SCPVMs of the string are known. Without any loss of generality, the SCPVMs will be ordered on the basis of current $I_{\text {cost }}$ (descending order): in particular, $I_{\text {cost }}(k) \geq I_{\text {cost }}(k+1)(k=$ $1,2, \ldots, N-1)$ and hence also $I_{0}(k) \geq I_{0}(k+1)(k=$ $1,2, \ldots, N-1)$. The $I-V$ equivalent characteristic of the string of SCPVMs can be obtained by evaluating, for each value of the current $I$, the corresponding value $V_{\text {tot }}$ of the string voltage. In practice, however, only the values $I=I_{\text {cost }}(k)$ and $I=I_{0}(k)(k=1,2, \ldots, N)$ need to be considered. In the following, we will assume that the set of currents $I_{\text {cost }}(k)$ and $I_{0}(k)(k=1,2, \ldots, N)$ is composed of $2 N$ different values. In correspondence with such $2 \mathrm{~N}$ values of currents, $3 \mathrm{~N}$ points of the $P-V$ characteristic can be found. In fact, for each value $I=I_{\text {cost }}(k)$, a couple of values of $V_{\text {tot }}$ and the corresponding couple of values of $P_{\text {tot }}=V_{\text {tot }} \cdot I$ are obtained. Therefore, $2 N$ points of the $P-V$ characteristic are associated with the $N$ values $I_{\text {cost }}(k)$. Instead, for each value $I=I_{0}(k)$, a single value of $V_{\text {tot }}$ and the corresponding value of $P_{\text {tot }}=V_{\text {tot }} \cdot I$ are obtained. Therefore, $N$ points of the $P-V$ characteristic are associated with the $N$ values $I_{0}(k)$. Moreover, the point $\left(V_{\text {tot }}=N V_{\text {ds max }}, I=0\right)$ of the $I-V$ characteristic and the corresponding point $\left(V_{\mathrm{tot}}=N V_{\mathrm{ds} \max }, P_{\text {tot }}=0\right)$ of the $P-V$ characteristic also need to be considered. The $P-V$ equivalent characteristic of the string of SCPVMs can be finally obtained by connecting the $(3 N+1)$ points obtained as explained before. As a general rule, when the current $I$ is equal to $I_{0}(k)$, then the contribution to the string voltage $V_{\text {tot }}$ provided by the $k$ th SCPVM is equal to $V_{\mathrm{ds} \text { max }}$. Instead, when the current $I$ is equal to $I_{\text {cost }}(k)$, then the contribution to the string voltage $V_{\text {tot }}$ provided by the $k$ th SCPVM can be any value belonging to the interval $\left[0, V_{\text {cost }}\right]$. Of course, should the set of currents $I_{\text {cost }}(k)$ and $I_{0}(k)(k=1,2, \ldots, N)$ be composed of less than $2 N$ different values (e.g., when the atmospheric operating conditions of 2 or more SCPVMs are identical), then, the corresponding set of points of the $P-V$ string characteristic is composed of less than $3 N+1$ different points. On the basis of the above considerations, it can be stated that

$$
\text { If } \begin{gathered}
I=I_{0}(k)=\frac{V_{\text {cost }} \cdot I_{\text {cost }}(k)}{V_{\mathrm{ds} \max }}=\frac{V_{\text {cost }} \cdot \beta I_{\mathrm{SC}}(k)}{V_{\mathrm{ds} \max }}, \\
V_{\text {tot }}=k \cdot V_{\mathrm{ds} \max }+\frac{\sum_{i \in J} V_{\text {cost }} \cdot I_{\text {cost }}(i)}{I_{0}(k)},
\end{gathered}
$$

where $k=1,2, \ldots, N$ and $J=\left\{i>k: I_{\text {cost }}(i)>I_{0}(k)\right\}$. In $(5)$ the set $J$ may also be empty. Consider

$$
\begin{gathered}
\text { If } I=I_{\text {cost }}(k)=\beta I_{\mathrm{SC}}(k), \\
V_{\text {tot }}=\left[m \cdot V_{\mathrm{ds} \max }+\frac{\sum_{i \in J} V_{\text {cost }} \cdot I_{\text {cost }}(i)}{I_{\text {cost }}(k)},\right. \\
\left.m \cdot V_{\mathrm{ds} \max }+\frac{\sum_{i \in J} V_{\text {cost }} \cdot I_{\text {cost }}(i)}{I_{\text {cost }}(k)}+V_{\text {cost }}\right],
\end{gathered}
$$

where $k=1,2, \ldots, N ; m=\max \left\{i<k: I_{0}(i)>I_{\text {cost }}(k)\right\}$; $J=\left\{m<i<k: I_{\text {cost }}(i)>I_{\text {cost }}(k)\right\}$ and the set $J$ may also be empty. Looking at (5) and (6), it is clear that the key is represented by currents $I_{\text {cost }}(k)=\beta I_{\mathrm{SC}}(k)(k=1,2, \ldots, N)$. Once $I_{\mathrm{SC}}(k)(k=1,2, \ldots, N)$ are known, then the whole $I-V$ 


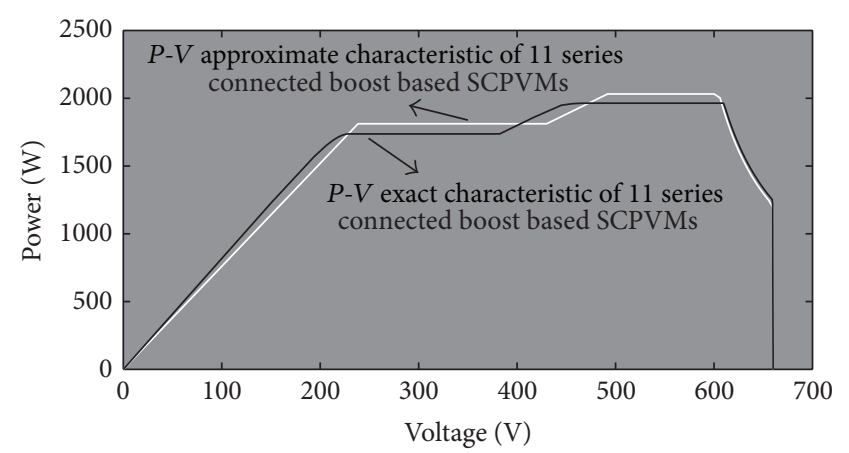

Figure 4: $P-V$ approximate and exact characteristics of 11 series connected boost based SCPVMs. $S=[1000,1000,1000,1000,1000$, $1000,1000,1000,1000,550,550] \mathrm{W} / \mathrm{m}^{2} ; T_{\text {ambient }}=25^{\circ} \mathrm{C} ; V_{\mathrm{ds} \max }=$ $60 \mathrm{~V}$.

(and hence the whole $P-V$ ) approximate characteristic of the string of SCPVMs can be obtained. In Figures 4 and 5, the approximate $P-V$ characteristics of eleven series connected SCPVMs, obtained by using (5) and (6), are compared to the exact characteristics. Figure 4 refers to the following values: $S=\left[\begin{array}{lllllllll}1000 & 1000 & 1000 & 1000 & 1000 & 1000 & 1000 & 1000 & 1000\end{array}\right.$ $550550] \mathrm{W} / \mathrm{m}^{2}, T_{\text {ambient }}=25^{\circ} \mathrm{C}$, and $V_{\mathrm{ds} \max }=60 \mathrm{~V}$, while Figure 5 refers to $S=\left[\begin{array}{llllll}1000 & 1000 & 1000 & 1000 & 1000 & 1000\end{array}\right.$ $400400400400400] \mathrm{W} / \mathrm{m}^{2}, T_{\text {ambient }}=25^{\circ} \mathrm{C}$, and $V_{\mathrm{ds} \max }=$ $60 \mathrm{~V}$.

As concerns Figure 4, it is worth noting that the midpoint $V_{\text {bulk_ref }}$ of the inverter optimal operating range $R_{b}$ provided by the approximate $P-V$ characteristic falls inside the exact inverter optimal operating range. As concerns Figure 5 instead, both the exact and the approximate inverter optimal operating ranges are indeed single points which differ by only a few volts. In conclusion, in both cases, the knowledge of the approximate $P-V$ characteristic allows to identify an inverter input voltage value $V_{\text {bulk_ref }}$ which is nearly coincident with the optimal value. That is, $V_{\text {bulk_ref }}$ is the inverter operating DC input voltage which allows maximizing the energetic efficiency of the whole system. This is a result with general validity; it holds with any arbitrary distribution of irradiance and temperature values. Equations (5) and (6) allow estimating not only the position and the amplitude of $R_{b}$ but also the maximum power $P_{b}$ that the system is able to provide. Such a piece of information, as shown in following, allows in turn estimating the optimal operating voltages $V_{\text {pan_ref }}(k)(k=1,2, \ldots, N)$ of all the PV modules.

In particular, in Figure 6, the flowchart of the HMPPT_F technique is shown. Such a technique can be divided into two steps. The first step is represented by the FEMPV algorithm which is based on the measurement of the short circuit current $I_{\mathrm{SC}}(k)(k=1,2, \ldots, N)$ of all the PV modules, in the considered atmospheric conditions, and on the subsequent estimate of a set of optimal operating voltages for the inverter $\left(V_{\text {bulk_ref }}\right)$ and for the SCPVMs $V_{\text {pan_ref }}(k)(k=1,2, \ldots, N)$. The FEMPV algorithm must take place periodically, with period $T_{m}$, and must have a duration equal to $\Delta t$. During $\Delta t$, the boost converters are forced to operate at a duty

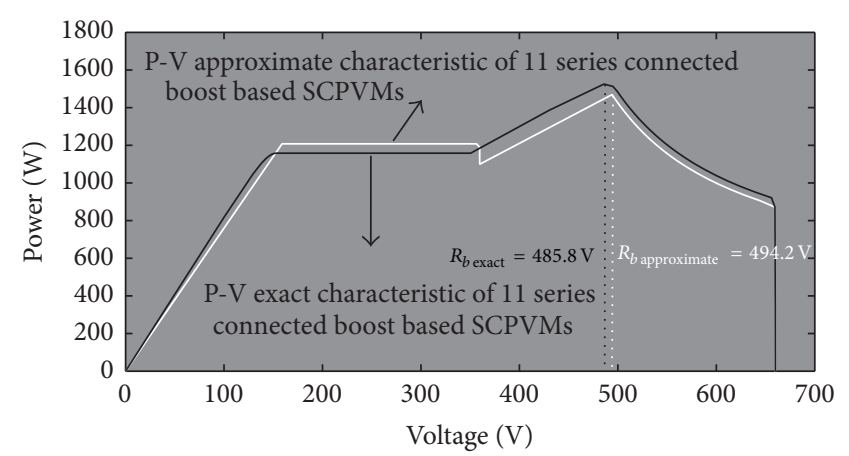

FIGURE 5: $P-V$ approximate and exact characteristics of 11 series connected boost based SCPVMs. $S=[1000,1000,1000,1000,1000$, $1000,400,400,400,400,400] \mathrm{W} / \mathrm{m}^{2} ; T_{\text {ambient }}=25^{\circ} \mathrm{C} ; V_{\mathrm{ds} \max }=60 \mathrm{~V}$.

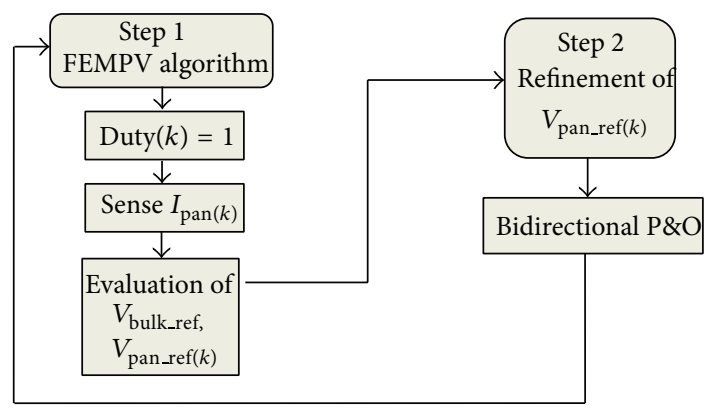

FIGURE 6: Flowchart of the HMPPT_F technique.

cycle nearly equal to one, so that the PV modules operate in short circuit conditions. The measurement of $I_{\mathrm{SC}}(k)(k=$ $1,2, \ldots, N)$ allows evaluating in closed form the approximate $P-V$ characteristic of the string of SCPVMs and then the approximate optimal operating range $R_{b}$, by using (5) and (6). The knowledge of $R_{b}$ allows evaluating $V_{\text {bulk_ref }}$ which is the middle point of $R_{b}$. Once $V_{\text {bulk_ref }}$ is known, it is then possible to evaluate $V_{\text {pan_ref }}(k)(k=1,2, \ldots, N)$. In particular, by indicating with $I_{h}$ the ratio $P_{b} / V_{\text {bulk_ref }}$, where $P_{b}$ is the maximum value of the power, we have that if $I_{h}>I_{\text {cost }}(k)$, then $V_{\text {pan_ref }}(k)=0$; if $I_{\text {cost }}(k)<I_{h}<I_{o}(k)$, then $V_{\text {pan_ref }}(k)=$ $V_{\text {cost }}$; if $I_{o}(k)<I_{h}<0$, then $V_{\text {pan_ref }}(k)=V_{\text {ds max }} * I_{h} / I_{\text {cost }}(k)$. It is worth noting that, for the sake of simplicity, all kinds of losses (in the SCPVMs and in the inverter itself) have been neglected in this paper. The actual efficiency of the power stage of the SCPVMs modifies the shape of the $P-V$ equivalent characteristic with respect to that one obtained by considering lossless SCPVMs and it is a complicated function of the operating point. Therefore, it would be nearly impossible to exactly consider it in the analytical evaluation of the estimate of the optimal range $R_{b}$. In order to take into account the inverter efficiency instead, the CMPPT technique should be carried out on the basis of calculations involving the inverter output power (CMPPT_out) rather than the inverter input power (CMPPT_in). Nearly always, in practical applications, CMPPT_in techniques are preferred thanks to their lower implementation cost (especially in three-phase applications) and thanks to the fact that if the efficiency of 


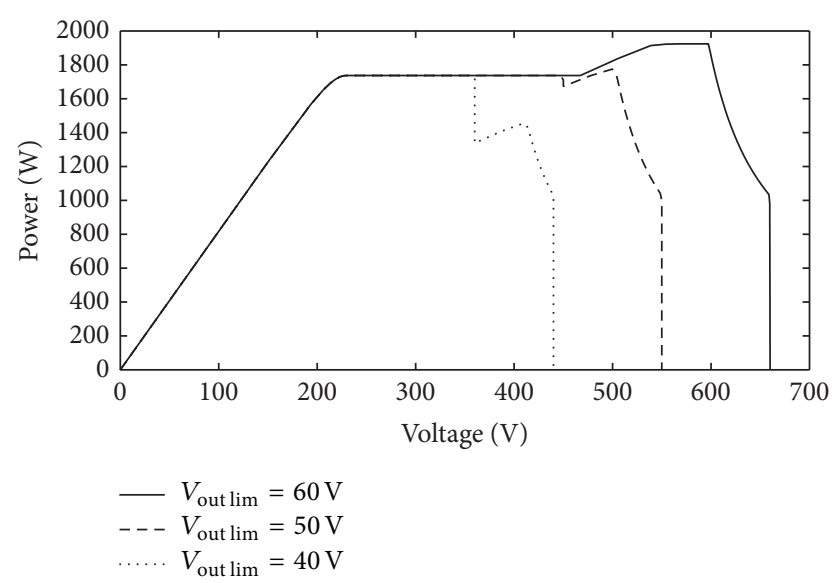

Figure 7: $P-V$ exact characteristics of 11 series connected boost based SCPVMs. $S=[1000,1000,1000,1000,1000,1000,400,400$, $400,400,400] \mathrm{W} / \mathrm{m}^{2} ; T_{\text {ambient }}=25^{\circ} \mathrm{C} ; V_{\mathrm{ds} \max }=60 \mathrm{~V}$.

the inverter is more or less flat in the MPPT inverter input voltage range, then CMPPT_in and CMPPT_out techniques are nearly equivalent to the efficiency point of view. In any case, if the inverter efficiency versus the DC inverter voltage $(\eta-V)$ curve is provided by the inverter manufacturer, the technique proposed in this paper can be very easily modified in order to take into account such an efficiency curve. In particular, the optimal inverter range $R_{b}$ can be evaluated with reference to the curve obtained by multiplying, point by point, the approximate $P-V$ curve with the $\eta-V$ curve, rather than with reference to the approximate $P-V$ curve. It is worth noting, however, that the estimates of $R_{b}$ and of the optimal PV modules voltages provided by the FEMPV algorithm can be further corrected by means of standard hillclimbing techniques implemented in the controllers of the SCPVMs and in the controller of the inverter, thus overcoming the errors associated with the various approximations and simplifications which have been adopted.

In the second step of the proposed HMPPT_F technique, an optimized $\mathrm{P} \& \mathrm{O}$ technique can be used to refine the values of $V_{\text {pan_ref }}(k)$ calculated at the end of the FEMPV algorithm. In particular, an optimized bidirectional $\mathrm{P} \& \mathrm{O}$ technique (BP\&O) is used, both to refine the value of $V_{\text {pan_ref }}(k)$ and to ensure that the output voltage of the $k$ th SCPVM is lower than $V_{\text {ds } \max }$.

The three parameters to fix in order to allow the working of the BP\&O technique are $\Delta V_{\mathrm{P} \& \mathrm{O}}, T_{a}$, and $V_{\text {out lim. }} . \Delta V_{\mathrm{P} \& \mathrm{O}}$ is the amplitude of the perturbation of the PV module voltage. $T_{a}$ is the time interval between two consecutive perturbations of the PV module voltage. $V_{\text {out } \lim }\left(V_{\text {out } \lim }<\right.$ $\left.V_{\mathrm{ds} \max }\right)$ is the voltage value which, if exceeded by the output voltage $v_{\text {out }}(k)$ of the $k$ th SCPVM, causes the inversion of the direction of the tracking of the $k$ th DMPPT controller. In particular, the BP\&O technique works as follows: when $v_{\text {out }}(k) \leq V_{\text {out lim }}$, then the BP\&O MPPT technique drives the $k$ th SCPVM in the direction of increasing output power $P_{\text {pan }}(k)$. Instead, when $v_{\text {out }}(k)>V_{\text {out lim }}$, it drives the $k$ th SCPVM in the direction of decreasing output power $P_{\text {pan }}(k)$. It is desirable to adopt a value of $V_{\text {out lim }}$ which is as high as possible since, depending on the distribution of irradiance values, in most cases the lower the $V_{\text {out lim }}$, the lower the maximum power which can be extracted from the PV systems [31, 32, 35]. As an example which confirms the above statement, in Figure 7, the PV characteristics of a string of 11 SCPVMs, obtained in correspondence with 3 different values of $V_{\text {out lim }}$, are reported. Figure 7 refers to $S=[1000,1000,1000,1000,1000,1000,1000,1000,1000$, $450,450] \mathrm{W} / \mathrm{m}^{2}$ and $T_{\text {ambient }}=25^{\circ} \mathrm{C}$. In other cases, the lower the $V_{\text {out lim }}$, the smaller the optimal range $R_{b}$ which may fall outside the inverter allowed operating range [31, 32, 35]. Therefore, the lower the $V_{\text {out lim }}$, the lower the energetic efficiency of the PV system.

In particular, it can be shown that the value adopted by $V_{\text {out lim }}$ must fulfill the following inequality [32, 34, 35]:

$$
\begin{aligned}
V_{\text {out lim }} \leq & \left(V_{\mathrm{ds} \max }\left(1-\frac{\Delta P_{\mathrm{pan}}}{P_{\mathrm{pan}}}\right)\right) \\
& \times\left(1+\frac{\left(N-N_{\mathrm{SC}}-2\right) \cdot \Delta P_{\mathrm{pan}}}{N \cdot V_{\mathrm{oc}} \cdot\left(P_{\mathrm{pan}} / V_{\mathrm{ds} \max }\right)}\right)^{-1},
\end{aligned}
$$

where $\Delta P_{\text {pan }}$ is the power variation of the $\mathrm{PV}$ module characterized by the highest value of the irradiance level in correspondence with a variation of amplitude equal to $\Delta V_{\mathrm{P \& O}}$ of the PV voltage, $P_{\mathrm{pan}}$ is the maximum power which can be extracted by the PV module characterized by the highest value of the irradiance level, and $N_{\mathrm{SC}}\left(N_{\mathrm{SC}} \leq N\right)$ is the number of SCPVMs with the output voltage equals 0 . In fact, the working conditions of the N SCPVMs depend on the distribution of irradiance values. In particular, some SCPVMs (those ones characterized by the highest irradiance values) may operate with an output voltage nearly equal to $V_{\text {out lim. }}$. Other SCPVMs may operate with an output voltage comprised between 0 and $V_{\text {out lim }}$ and, finally, the remaining $N_{\text {SC }}$ SCPVMs (those ones characterized by the lowest irradiance values) may operate with output short-circuit conditions [32]. Of course, $N_{\mathrm{SC}}$ can also be equal to 0 . It is worth noting, however, that when adopting the HMPPT_S technique, no prior estimation of $N_{\mathrm{SC}}$ is possible. Therefore, as a worst case, it must be assumed that $N_{\mathrm{SC}}=0$ in (7). Instead, when adopting the HMPPT_F technique, it is possible to evaluate the actual number $N_{\mathrm{SC}}$. Moreover, also the quantity $\Delta P_{\mathrm{pan}} / P_{\mathrm{pan}}$ appearing in (7) can be more or less accurately estimated when adopting the HMPPT_F technique. Instead, in the case of the HMPPT_S technique, only a worst-case value can be adopted [33]. As a consequence, in general, the value of $V_{\text {out lim }}$ to be adopted when using the HMPPT_S technique is higher than the corresponding one to be adopted when using the HMPPT_F technique. Therefore, the energetic efficiency obtained when adopting the HMPPT_S technique is expected to be lower than the energetic efficiency obtained when using the HMPPT_F technique.

\section{Simulation Results}

The system shown in Figure 8 and adopting the HMPPT_F technique has been simulated by using PSIM (simulation 


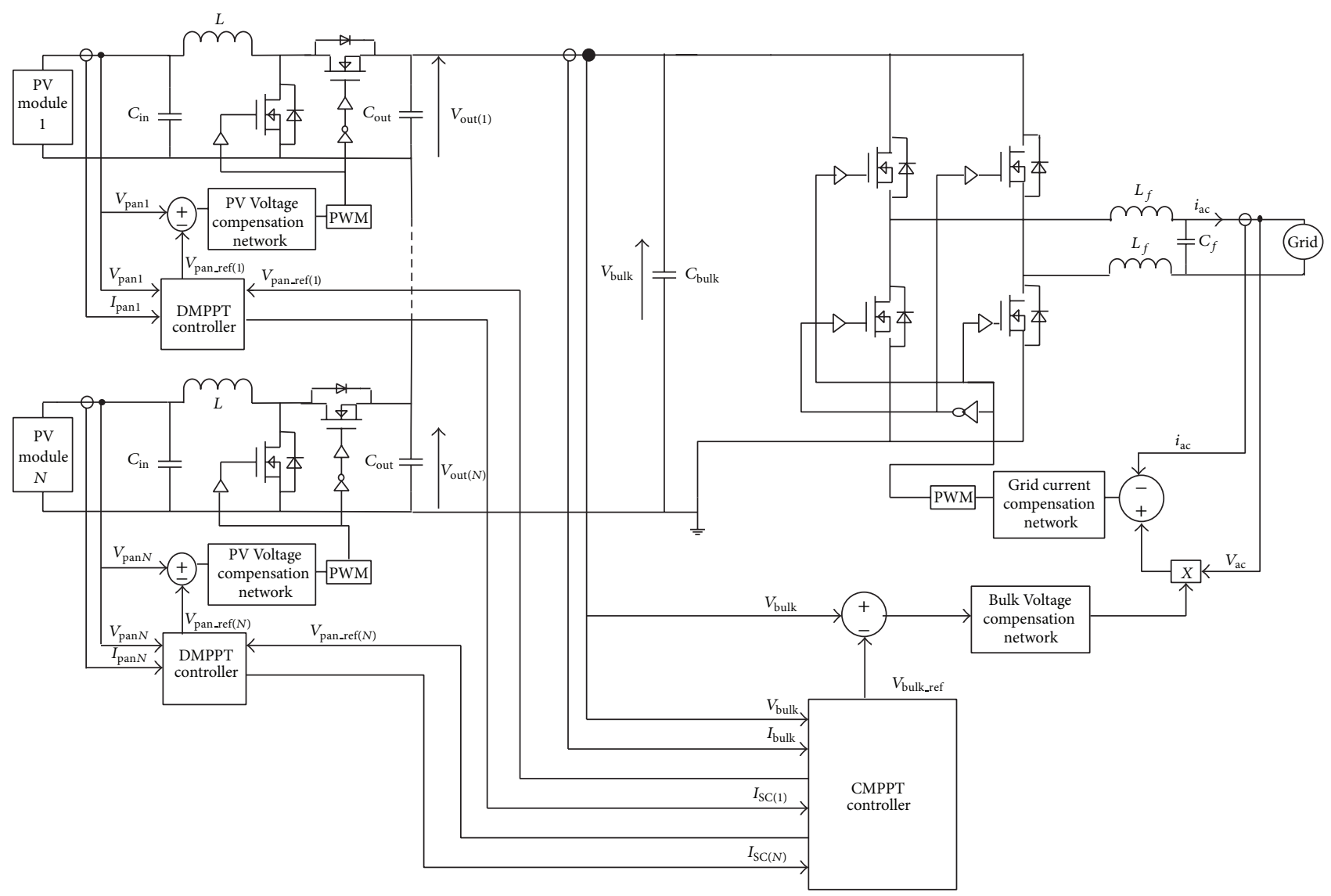

FIGURE 8: PV grid-connected system simulated in PSIM environment.

software for power conversion and control) in the following operating conditions: $S=[1000,1000,1000,1000,1000$, $1000,1000,400,400,400,400] \mathrm{W} / \mathrm{m}^{2} ; \quad T_{\text {ambient }}=25^{\circ} \mathrm{C}$; $V_{\text {ds max }}=60 \mathrm{~V}$. The source is composed of a string of $N=11$ SCPVMs that feed a full-bridge inverter. In the case of grid-connected inverters with full-bridge topology, with reference to European installations $\left(230 \mathrm{~V}_{\text {rms }}\right.$ grid voltage), a typical allowed inverter input voltage range is [360-600] V. A DC inverter input voltage lower than the left extreme of such a range $(360 \mathrm{~V})$ does not allow for the desired operation of the inverter since, in the worst case, the DC inverter input voltage must be greater than the peak value of the grid voltage plus the additional voltage drops taking place between the inverter bulk capacitor and the grid. Therefore, the search for the optimal value $V_{\text {bulk_ref }}$ must be confined in the allowed input voltage inverter range.

The allowed inverter input voltage range is therefore $[360,660] \mathrm{V}$. The switching frequency $f_{s}$ of the boost converters and of the full-bridge inverter has been chosen equal to $50 \mathrm{kHz}$. Moreover $\mathrm{L}=100 \mu \mathrm{H}, C_{\text {in }}=220 \mu \mathrm{F}, L_{f}=330 \mu \mathrm{H}$, $C_{f}=47 \mu \mathrm{F}, C_{\text {bulk }}=1 \mathrm{mF}$, and $C_{\text {out }}=330 \mu \mathrm{F}$. The guidelines allowing the design of the PV voltage compensation network, the inverter bulk voltage compensation network, and the grid current compensation network can be found in $[32,38]$. The value of $\Delta t$ is equal to $1 \mathrm{~s}$. The results of simulations will be compared with those ones obtained by using the HMPPT_S technique. Both the HMPPT_F and the HMPPT_S technique share the same BP\&O DMPPT technique.

In particular, the values of $\Delta V_{\mathrm{P} \& \mathrm{O}}$ and $T_{a}$ are the same for both the HMPPT_F and the HMPPT_S techniques $\left(\Delta V_{\mathrm{P} \& \mathrm{O}}=\right.$ $\left.0.15 \mathrm{~V}, T_{a}=1.5 \mathrm{~ms}\right)$. The guidelines allowing the choice of $\Delta V_{\mathrm{P} \& \mathrm{O}}$ and $T_{a}$ can be found in [1]. The two parameters of the CMPPT technique based on the periodic scan of the whole $P-V$ characteristic of the string of SCPVMs are the amplitude $\Delta v_{b_{\text {_ref }}}$ of the steps of the staircase reference signal for the inverter DC input voltage and the duration $T_{b}$ of each step. It is worth noting that the curve which is scanned in the HMPPT_S technique is not the $P-V$ curve of the string of PV modules. Such a curve is useless in DMPPT PV applications, since the PV modules are not series connected but each of them feeds its own DC/DC converter. The curve which is scanned is instead of the $P-V$ curve of the string of SCPVMs, that is, the $P-V$ curve at the input of the inverter. Therefore, such a scanning does not require the disconnection from the grid since it is carried out by means of a suitable staircase signal which is periodically provided by the inverter controller and is adopted as a reference to be followed by the inverter DC input voltage.

The guidelines allowing the choice of $\Delta v_{b \_ \text {ref }}$ and $T_{b}$ can be found in [33]: $\Delta v_{b_{-} \text {ref }}=25 \mathrm{~V}$ and $T_{b}=0.9 \mathrm{~s}$. By using 


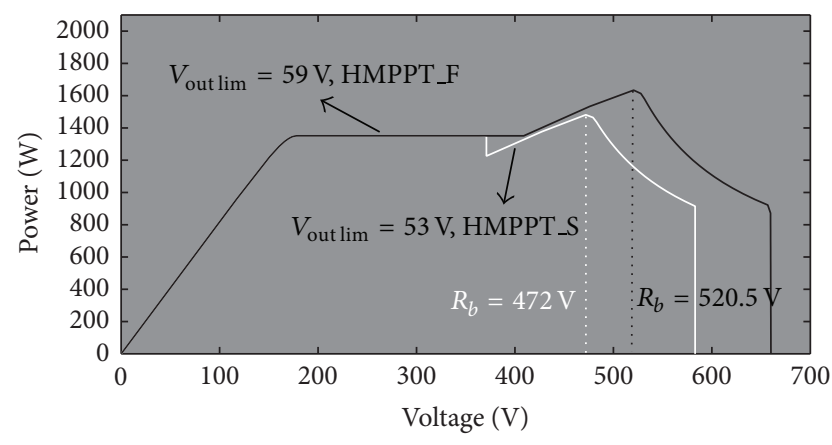

Figure 9: $P-V$ characteristics. $S=[1000,1000,1000,1000,1000$, $1000,1000,400,400,400,400] \mathrm{W} / \mathrm{m}^{2} ; T_{\text {ambient }}=25^{\circ} \mathrm{C}$.

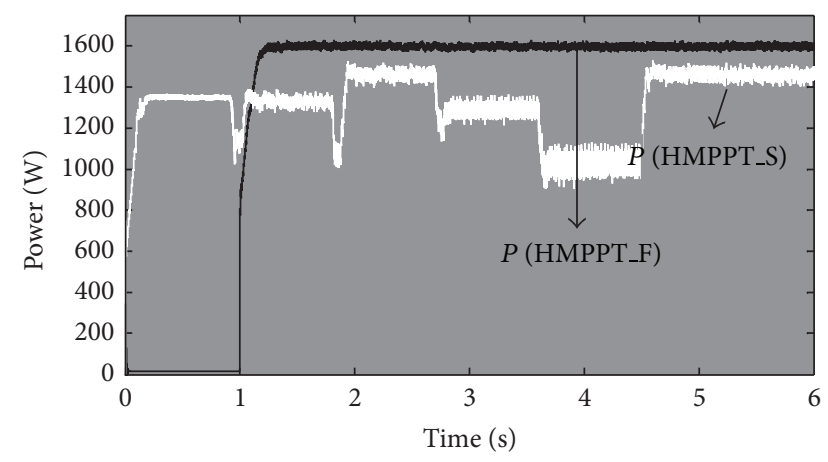

FIGURE 10: Time-domain behavior of the power extracted by using the HMPPT_F and the HMPPT_S technique. $S=[1000,1000,1000$, $1000,1000,1000,1000,400,400,400,400] \mathrm{W} / \mathrm{m}^{2} ; T_{\text {ambient }}=25^{\circ} \mathrm{C}$.

(7), we get $V_{\text {out_lim }}=53 \mathrm{~V}$ in the case of the HMPPT_S technique, and $V_{\text {out_lim }}=59 \mathrm{~V}$ in the case of the HMPPT_F technique. In Figure 9, the $P-V$ characteristics of the string of the SCPVMs are reported with reference to such two distinct values of $V_{\text {out_lim }}$. Figure 10 shows the time-domain behavior of the power $P$ extracted by using both the HMPPT_S and the HMPPT_F techniques. Figure 11 instead shows the corresponding time-domain behavior of the input inverter voltage $v_{\text {bulk }}$.

Two main aspects are worth noting. The first one is that, as predicted by Figure 9, the steady-state value of the power $P$ in the case of the HMPPT_F technique $(1634 \mathrm{~W})$ is greater than the corresponding one obtained by using the HMPPT_S technique $(1481 \mathrm{~W})$. The second aspect, which is another important drawback of the HMPPT_S technique, is instead represented by the higher speed of tracking exhibited by the HMPPT_F technique. The HMPPT_F technique is able to get the maximum power much before the HMPPT_S technique which instead needs to wait the time necessary for whole scan (4.5 s).

\section{Hardware Implementation}

As it is illustrated in Figure 2, every SCPVM and the central inverter need a dedicated embedded measurement system (EMS) which has to implement the control techniques described before $[33,39]$. In particular, the EMS of any

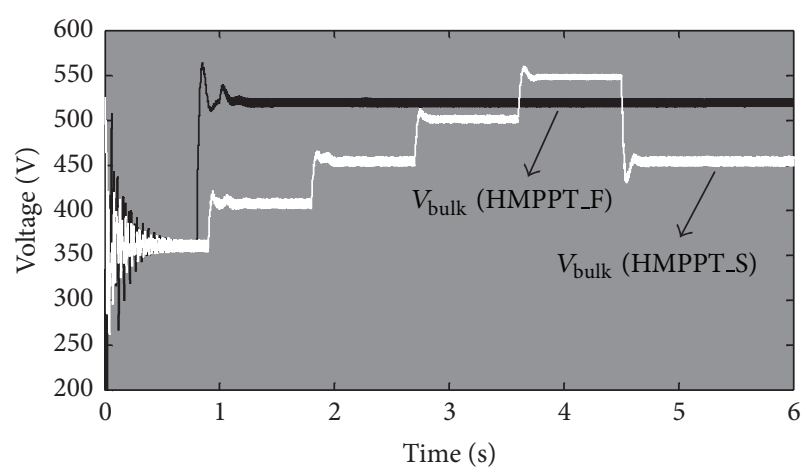

FIGURE 11: Time-domain behavior of the input inverter voltage obtained by using the HMPPT_F and the HMPPT_S technique. $S=$ $[1000,1000,1000,1000,1000,1000,1000,400,400,400,400] \mathrm{W} / \mathrm{m}^{2}$; $T_{\text {ambient }}=25^{\circ} \mathrm{C}$.

SCPVM has to implement the DMPPT technique, sending the value of the short circuit current $I_{\mathrm{SC}}(k)$ to the EMS of the central inverter and receiving from it the value of the reference voltage $V_{\text {pan_ref }}(k)$. The EMS of the central inverter, in turn, implements the CMPPT technique along with the FEMPV algorithm. In order to implement the DMPPT technique, the EMS of each SCPVM has to measure the input voltage, the input current, and the output voltage of the boost converter. The EMS of the inverter has to measure the input current and the input voltage of the inverter. Moreover, all the EMSs must communicate over a digital bus, in order to exchange the information concerning the application of the FEMPV algorithm. In order to prove the effectiveness of the proposed technique, a laboratory test system has been implemented. For the sake of simplicity, it is composed of only two SCPVMs and a central inverter. The schematic block diagram of the experimental setup is shown in Figure 12; the single components are described in the following subsections.

\subsection{Emulators of the Photovoltaic Modules and of the Inverter.} In order to be able to carry out repeatable experiments, under controllable solar irradiance, the two PV modules have been emulated by means of two numerically controlled four quadrant power sources. In particular, the adopted power sources are Kepco BOP 36-12 M; they are $400 \mathrm{~W}$ power supplies whose main specifications are reported in Table 1. Such power supplies digitally communicate over an IEEE 488 digital bus, through which they can be programmed in order to emulate the PV panels.

The Kepco BOP 36-12 M power source can be used both in voltage as well as in current mode, that is, as a voltage or as a current generator. This is an important feature, since it allows connecting two or more units, emulating PV modules, in series (as voltage generators) or in parallel (as current generators). Thus, it is possible to realize flexible and complex PV systems. The two units have been used to emulate two PV modules with the specifications reported in Table 2.

As it can be seen from Table 2, it has been assumed that the two emulated PV modules are exposed to two different solar radiations. The different solar radiations give 


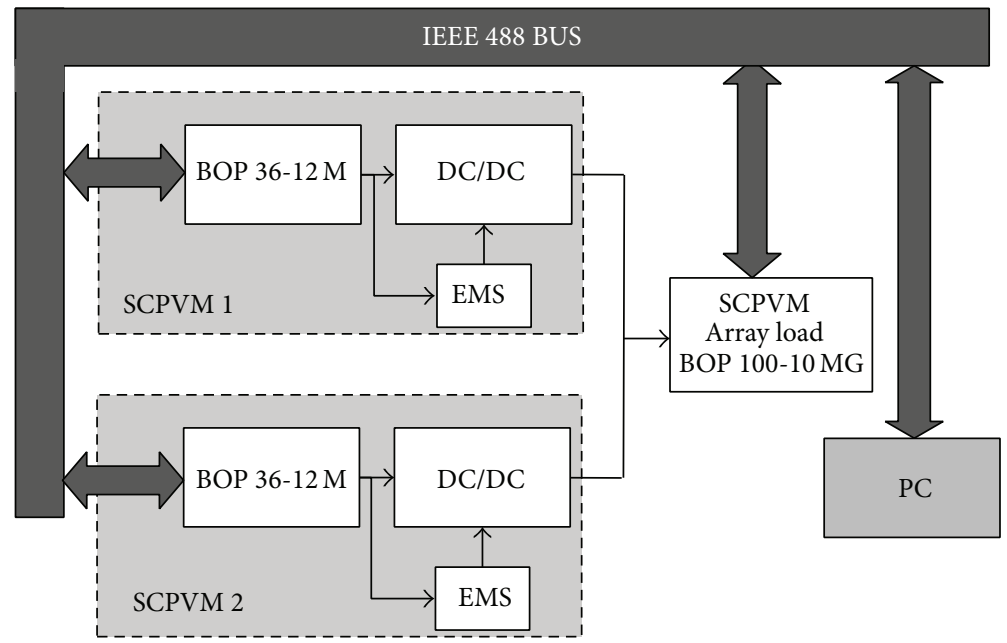

FIGURE 12: Schematic block diagram of the experimental setup.

TABLE 1: Main specifications of the power supply which emulates a PV module.

\begin{tabular}{|c|c|c|c|c|c|c|c|c|}
\hline \multirow{3}{*}{ Model } & \multirow{2}{*}{\multicolumn{2}{|c|}{ DC output range }} & \multirow{2}{*}{\multicolumn{2}{|c|}{ Closed loop gain }} & \multicolumn{4}{|c|}{ Output impedance } \\
\hline & & & & & Volt & hode & Curr & node \\
\hline & $E_{O} \max$ & $I_{O} \max$ & $\begin{array}{c}\text { Voltage } \\
\text { channel } \\
G_{V} \\
(\mathrm{~V} / \mathrm{V})\end{array}$ & $\begin{array}{c}\text { Current } \\
\text { channel } \\
G_{A} \\
(\mathrm{~A} / \mathrm{V})\end{array}$ & Series R & Series L & Shunt R & Shunt C \\
\hline BOP $36-12 \mathrm{M}$ & $\pm 36 \mathrm{~V}$ & $\pm 12 \mathrm{~A}$ & 3.6 & 1.2 & $60 \mu \Omega$ & $50 \mu \mathrm{H}$ & $36 \mathrm{k} \Omega$ & $0.4 \mu \mathrm{F}$ \\
\hline
\end{tabular}

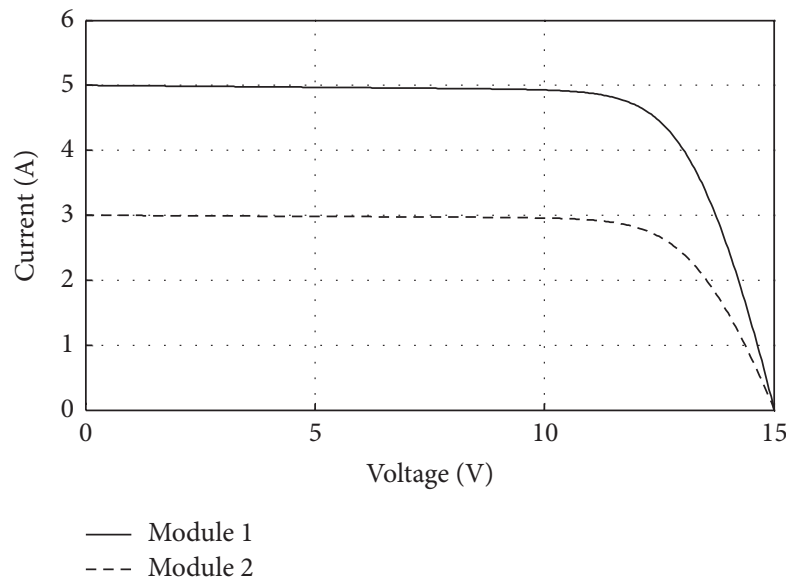

FIgURE 13: Current versus voltage characteristics of the two emulated PV modules.

rise to two different current versus voltage characteristics of the two emulated modules; such characteristics are reported in Figure 13.

The input port of the central inverter has been emulated by means of a Kepco BOP 100-10 MG operating as an electronic load. Its main specifications are reported in Table 3. Also, the Kepco BOP 100-10 MG supply is managed through
TABLE 2: Main specifications of the emulated PV modules.

\begin{tabular}{lccc}
\hline & $\begin{array}{c}\text { Solar } \\
\text { radiation } \\
{\left[\mathrm{W} / \mathrm{m}^{2}\right]}\end{array}$ & $\begin{array}{c}\text { Open circuit } \\
\text { voltage }\left(V_{\mathrm{OC}}\right) \\
{[\mathrm{V}]}\end{array}$ & $\begin{array}{c}\text { Short circuit } \\
\text { current }\left(I_{\mathrm{SC}}\right) \\
{[\mathrm{A}]}\end{array}$ \\
\hline Module 1 & 1000 & 15 & 5 \\
Module 2 & 600 & 15 & 5 \\
\hline
\end{tabular}

an IEEE 488 bus and is used to set a constant voltage across the two series connected SCPVMs.

4.2. The DC/DC Converters. Two specifically designed boost converters have been used. The adopted circuital scheme is reported in Figure 8. The boost converters have been designed according to [32]. The main design specifications are reported in Table 4 . The inductance is about $300 \mu \mathrm{H}$, the input capacitance is about $6.8 \mu \mathrm{F}$, and the output capacitance is about $10 \mu \mathrm{F}$.

4.3. The Embedded Measurement Systems. As EMSs, the microcontrollers STM32F407VGT6 from ST Microeletronics have been used. The STM32F407xx family is based on the high-performance ARM Cortex-M4 32-bit RISC core operating at a frequency up to $168 \mathrm{MHz}$. The Cortex-M4 core features a floating point unit (FPU) single precision which supports all ARM single precision data-processing instructions and data types. It also implements a full set 
TABle 3: Main specifications of the power supply which emulates the PV array load.

DC output range Closed loop gain Output impedance

\begin{tabular}{|c|c|c|c|c|c|c|c|c|}
\hline \multirow[b]{2}{*}{ Model } & \multirow[b]{2}{*}{$E_{O} \max$} & \multirow[b]{2}{*}{$I_{O} \max$} & \multirow[b]{2}{*}{$\begin{array}{c}\text { Voltage channel } \\
G_{V} \\
(\mathrm{~V} / \mathrm{V})\end{array}$} & \multirow[b]{2}{*}{$\begin{array}{c}\text { Current channel } \\
\qquad G_{A} \\
(\mathrm{~A} / \mathrm{V})\end{array}$} & \multicolumn{2}{|c|}{ Voltage mode } & \multicolumn{2}{|c|}{ Current mode } \\
\hline & & & & & Series R & Series L & Shunt R & Shunt C \\
\hline BOP $100-10 \mathrm{MG}$ & $\pm 100 \mathrm{~V}$ & $\pm 10^{\circ}$ & 10.0 & 1.0 & $10 \mathrm{~m} \Omega$ & $163 \mu \mathrm{H}$ & $5000 \Omega$ & $16 \mu \mathrm{F}$ \\
\hline
\end{tabular}

TABLE 4: Main specifications of the boost converter utilized in the SCPVM.

\begin{tabular}{lc}
\hline Input voltage: & 0 to $20 \mathrm{~V}$ \\
Input current: & 0 to $5 \mathrm{~A}$ \\
Output voltage: & 0 to $40 \mathrm{~V}$ \\
Output current: & $2.5 \mathrm{~A}, V_{\text {out }}=40 \mathrm{~V}$ \\
Input voltage ripple, max: & $1 \% V_{\text {in_max }}$ \\
Inductor current ripple: & $10 \% I_{\text {in_max }}$ \\
Output voltage ripple, max: & $4 \% V_{\text {out_max }}$ \\
Switching frequency: & $30 \mathrm{kHz}$ \\
\hline
\end{tabular}

of DSP instructions and a memory protection unit (MPU) which enhances application security. The STM32F407xx family incorporates high-speed embedded memories (flash memory of up to 1 Mbyte, up to 192 kbytes of SRAM) of up to 4 kbytes of backup SRAM and an extensive range of enhanced I/Os and peripherals connected to two APB buses, three AHB buses, and a 32-bit multi-AHB bus matrix. All devices offer three 12-bit ADCs, two DACs, a low-power RTC, and twelve general-purpose 16-bit timers including two PWM timers for motor control, two general-purpose 32-bit timers, and a true random number generator (RNG). They also feature standard and advanced communication interfaces, such as I2C, SPI, USART, UART, USB, CAN, SDIO/MMC, and Ethernet.

The EMSs measure the input and the output voltages of the boost converters by means of simple resistive voltage dividers, with a high impedance voltage buffer, and their input currents by means of current transducers ACS712 from Allegro MicroSystems. The EMS of the central inverter measures its input voltage by means of the insulated voltage transducer LV-25P from LEM; in fact, differently from the SCPVMs, now galvanic insulation between voltage sources and signal acquisition unit is needed. The input current of the inverter is measured through another ACS712, which is an insulated transducer. The EMSs communicate among themselves through CAN bus: every EMS is equipped with optical digital insulators at CAN bus pins, in order to assure the galvanic insulation among EMSs.

\section{Experimental Results}

The experimental tests have been carried out in order to characterize the emulators of the PV modules and the SCPVMs. That is in order to obtain the experimental $I-V$ and $P-V$ static characteristics of the emulated PV modules and of the SCPVMs.

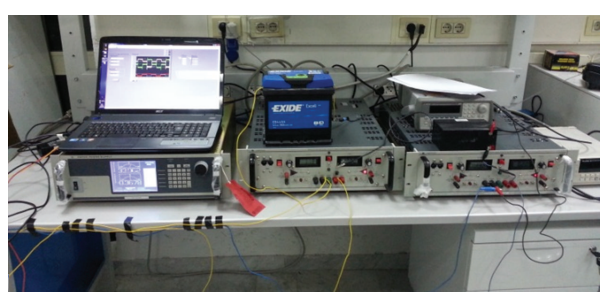

FIGURE 14: Photo of the experimental setup: two power amplifiers emulate the PV modules and one power amplifier emulates the load.

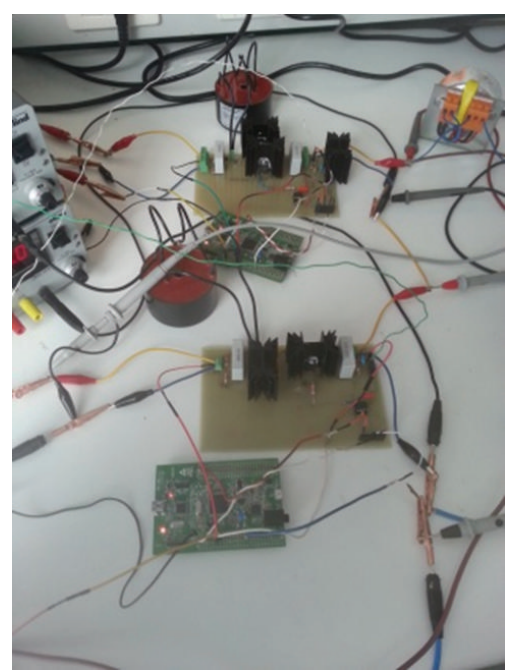

FIGURE 15: Photo of the experimental setup: two EMSs and two boost converters.

In order to measure the static characteristics, the Yokogawa WT500 wattmeter, whose specifications are reported in [40], has been adopted. For the characterization of the system, a measurement station has been used. It was composed of (1) a personal computer; (2) a data acquisition board with four analog inputs, range of $\pm 10 \mathrm{~V}$, resolution of $16 \mathrm{bits}$, and sampling frequency of $100 \mathrm{kHz} /$ channel; (3) three LEM CV31000 as voltage transducers; (4) three LEM CT10 as current transducers. Two photos of the experimental setup are shown in Figures 14 and 15.

The $I-V$ curves of the two emulated PV modules are shown in Figures 16 and 17. They have been obtained by setting a time-varying voltage, through the Kepco BOP 100$10 \mathrm{MG}$ described in Table 3, at the terminal of the emulated PV modules. For this test, the emulated PV modules have been characterized one at a time. By varying the voltage across 


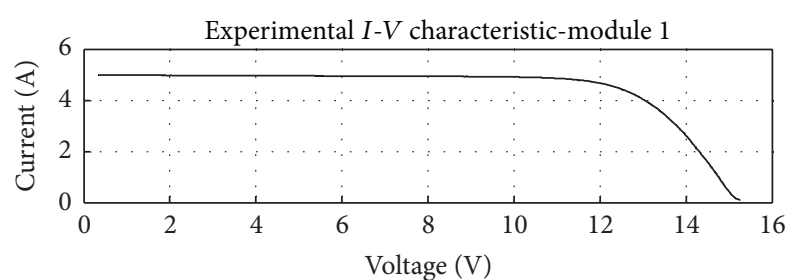

(a)

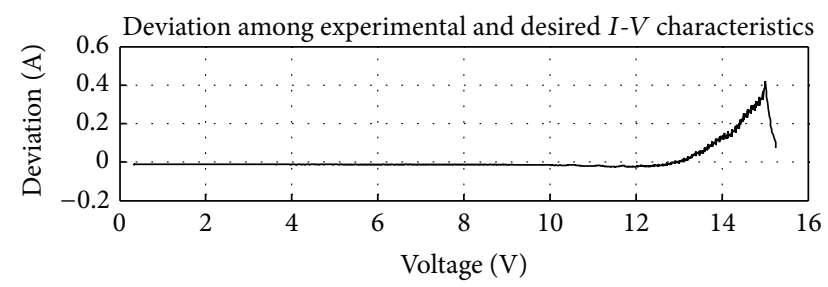

(b)

FIGURE 16: $I-V$ characteristic of emulated PV module 1 and deviation with respect to the desired one.

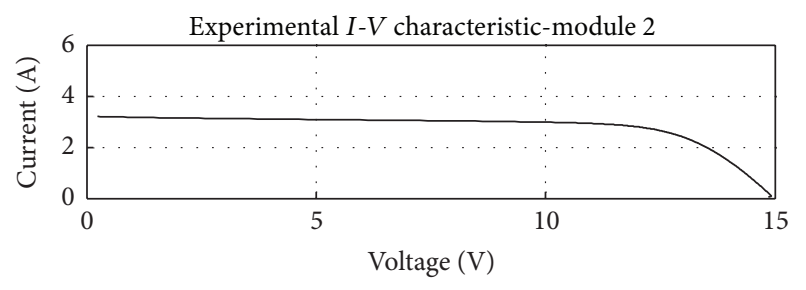

(a)

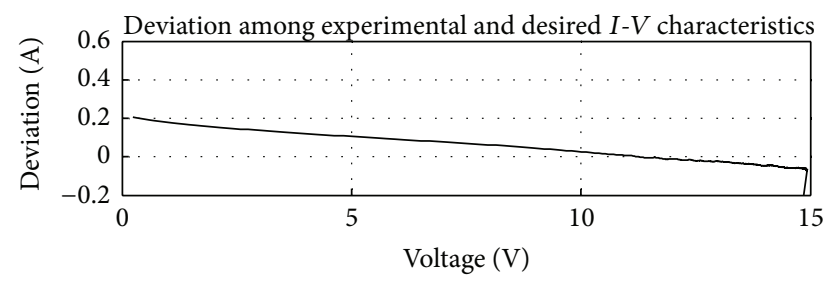

(b)

FIgURE 17: $I-V$ characteristic of the emulated PV module 2 and deviation with respect to the desired one.

the emulated PV modules terminals and by measuring the corresponding currents, the $I-V$ curves can be obtained. In Figures 16 and 17, the deviations with respect to the desired characteristics of Figure 13 are shown.

The same test has been performed by connecting the two modules in series. The $P$ - $V$ curve of the two series connected modules is shown in Figure 18. It can be seen that, since the two modules are exposed to different solar radiations, the $P-V$ curve exhibits two maxima. The maximum power is reached in correspondence with about $25 \mathrm{~V}$ and it is equal to about $65 \mathrm{~W}$. The relative maximum power point is located at about $11 \mathrm{~V}$, and its power is equal to about $52 \mathrm{~W}$.

Then, the emulated PV modules have been connected to the corresponding boost DC/DC converters and EMSs, in order to obtain two SCPVMs. The two SCPVMs have been characterized in the same way of the two emulated PV

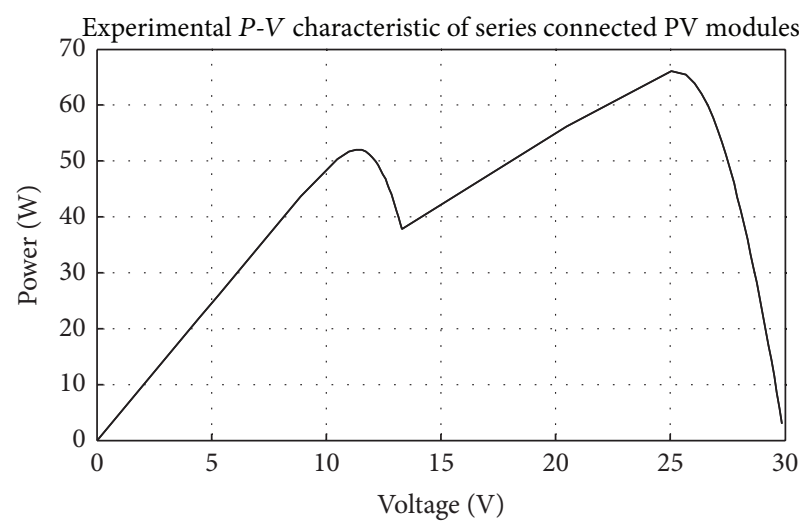

FIgURE 18: $P-V$ characteristic of the two series connected emulated $\mathrm{PV}$ modules.

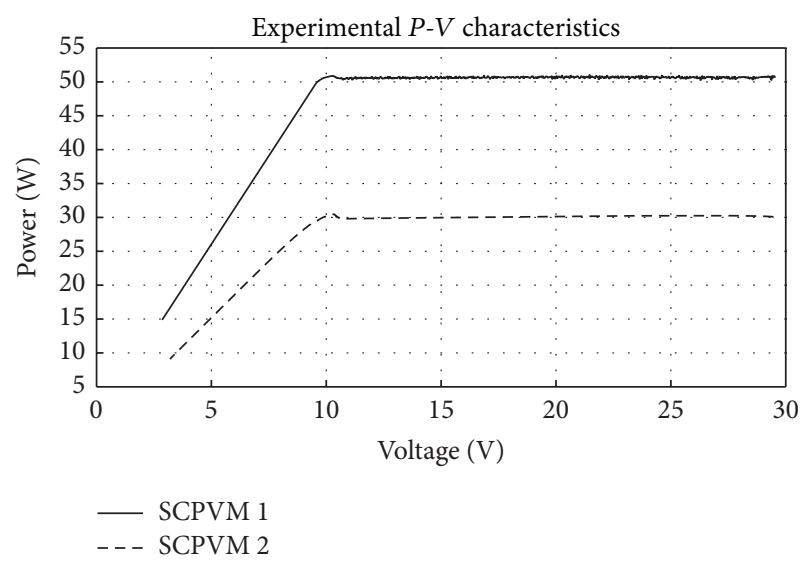

FIGURE 19: Output powers of the emulated PV modules versus the output voltage of the corresponding SCPVMs.

modules, as described at the beginning of this subsection, that is, by setting a time-varying voltage and by measuring the corresponding current. In this test, they have not been connected in series and they have been characterized one at a time. Figure 19 shows the output powers of the emulated $\mathrm{PV}$ modules versus the output voltage of the corresponding SCPVMs. As it can be seen, until the output voltage of the SCPVM does not reach the maximum power point voltage $V_{\mathrm{MPP}}$, the power increases with the voltage; in these conditions, the EMS lets the boost converter work at zero duty cycle; that is, the boost input and output voltages values are the same. When the output voltage of the SCPVM reaches $V_{\mathrm{MPP}}$, the EMS forces the boost to increase its duty cycle, in order to maintain $V_{\mathrm{MPP}}$ across the emulated PV module. Therefore, even in correspondence with SCPVMs output voltages values which are higher than $V_{\mathrm{MPP}}$, the output powers of the emulated PV modules are constant and equal to their maximum possible value.

The same test has been performed by connecting the two SCPVMs in series. Figure 20 shows the $P-V$ characteristic of the two series connected SCPVMs. Comparing such a curve with the $P-V$ characteristic of Figure 18, some considerations can be drawn. First of all, the PV maximum power extracted 


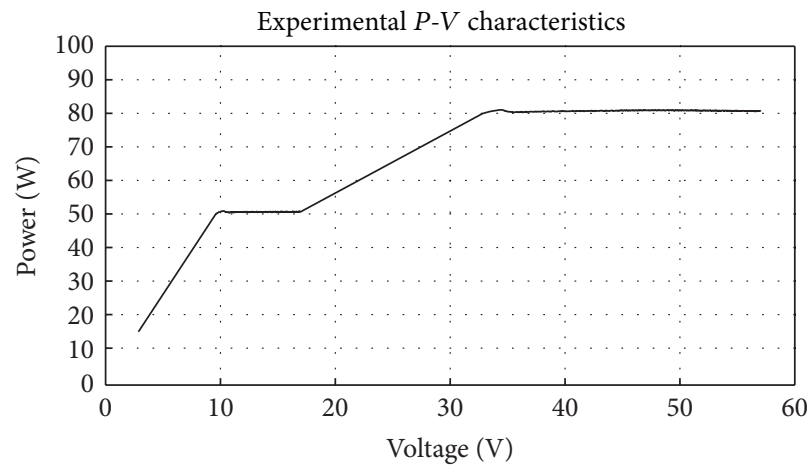

FIgURe 20: $P-V$ characteristic of the string of the two SCPVMs.

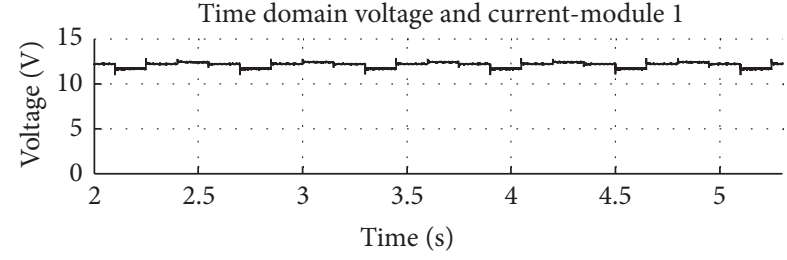

(a)

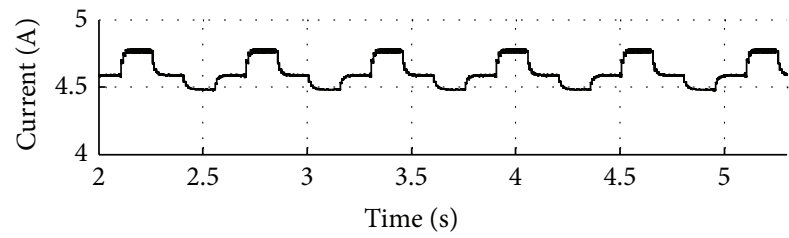

(b)

FIgURE 21: Steady-state voltage and current of the emulated PV module 1 in the first test.

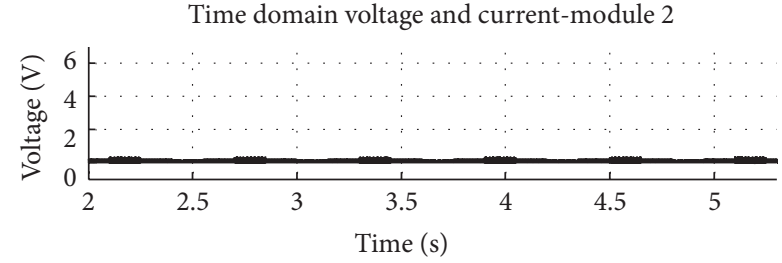

(a)

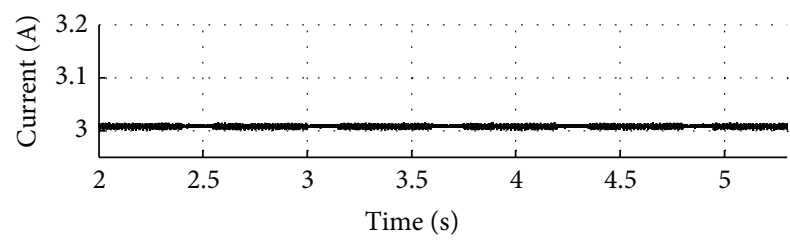

(b)

FIGURE 22: Steady-state voltage and current of the emulated PV module 2 in the first test.

in the case of the string of SCPVMs (about $73 \mathrm{~W}$ ) is higher than the corresponding power obtained in the case of the string of PV modules (about $65 \mathrm{~W}$ ). Secondly, in the case of the string of SCPVMs, there are no local maxima in which the CMPPT inverter controller can force the system to work. Thirdly, in the case of the string of SCPVMs, the power is constant and assumes its maximum value in a wide voltage range (from about $27 \mathrm{~V}$ to about $65 \mathrm{~V}$ ) rather than in a single operating point (i.e., $25 \mathrm{~V}$ in Figure 18).

It is important to underline that such experimental results are in full agreement with the theoretical predictions discussed in Section 2.

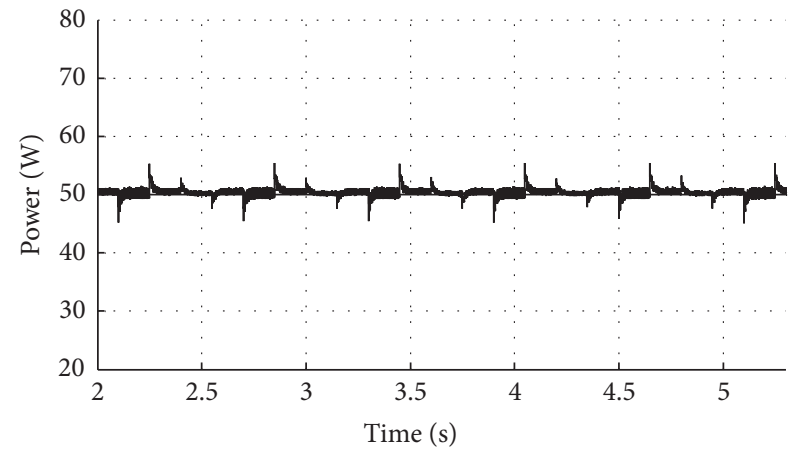

FIGURE 23: Steady-state total output power of the series connected SCPVMs in the first test.

In order to obtain a further verification of the theoretical predictions, two additional tests have been performed. In the first test, the string of the two SCPVMs is forced to work with a constant voltage equal to about $15 \mathrm{~V}$. Figure 21 shows the steady-state voltage and the steady-state current of the emulated PV module 1, while Figure 22 shows the steadystate voltage and the steady-state current of the emulated PV module 2. Figure 23 shows instead the total steady-state output power of the two emulated PV modules. In accordance with the theoretical predictions, it can be seen that the module exposed to the lower solar radiation provides no output power at the steady-state since it works in output short circuit conditions. Coherently with Figure 19, from Figure 23, it can be seen that the total output power corresponds to the output power of the only PV module 1 and it is equal to about $56 \mathrm{~W}$. 


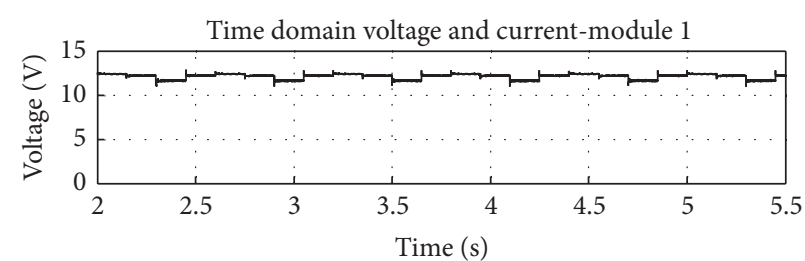

(a)

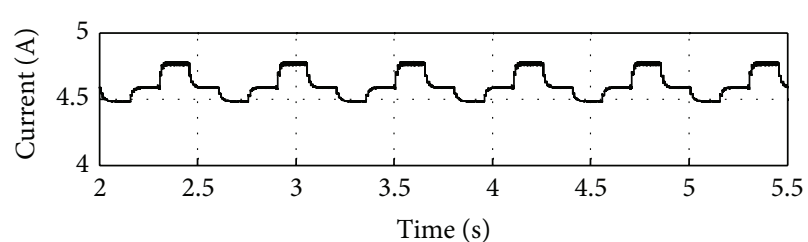

(b)

FIGURE 24: Steady-state voltage and current of the emulated PV module 1 in the second test.

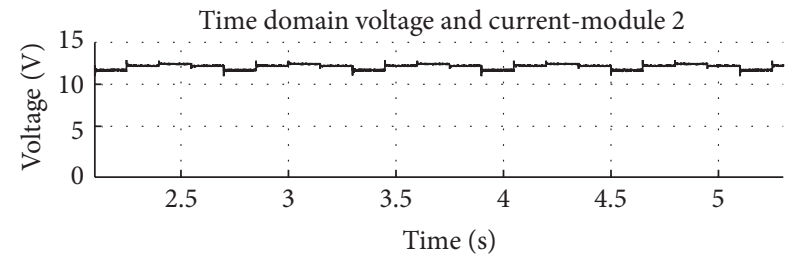

(a)

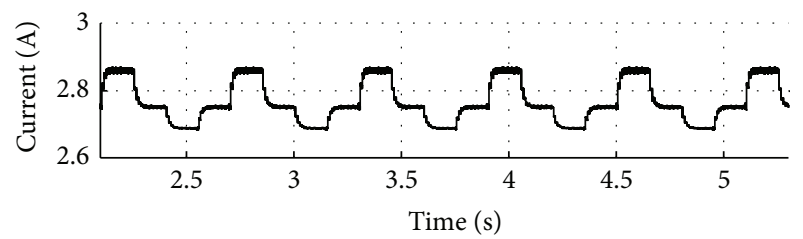

(b)

FIgURE 25: Steady-state voltage and current of the emulated PV module 2 in the second test.

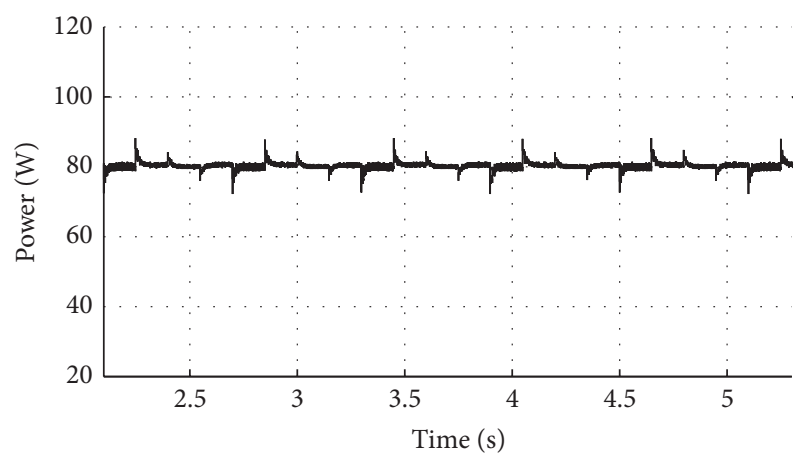

FIGURE 26: Steady-state total output power of the series connected SCPVMs in the second test.

In the second test, the string of SCPVMs is forced to work with a constant voltage equal to about $45 \mathrm{~V}$. Figure 24 shows the steady-state voltage and the steady-state current of the emulated PV module 1, while Figure 25 shows the steadystate voltage and the steady-state current of the emulated PV module 2. Figure 26 shows the total steady-state output power of the series connected SCPVMs. In this case, in accordance with the theoretical predictions, it can be seen that both the two modules provide their maximum power. Coherently with Figure 19, from Figure 26, it can be seen that the total output power corresponds to the sum of the output powers of module 1 and module 2 and it is equal to about $89 \mathrm{~W}$.

\section{Conclusions}

In PV applications, under mismatching conditions, the adoption of a MPPT technique which is able to regulate not only the voltages of the PV modules of the array but also the DC input voltage of the inverter is necessary. Such a technique can be considered a hybrid MPPT technique which is neither only distributed on the PV modules of the PV array or only centralized at the input of the inverter. In this paper, a new HMPPT technique is presented and discussed. Its main advantages are the high MPPT efficiency and the high speed of tracking obtained by means of a fast estimate of the optimal voltages of the PV modules and of the inverter. The mathematical formulation of the technique has been deeply discussed. Numerical simulations allowing comparing the performances of the presented technique with those ones of another HMPPT technique have been also shown. A prototype of the embedded measurement system which has to be applied to each PV module in order to implement the DMPPT technique has been realized. The different embedded measurement systems of the same PV plant can communicate among themselves through optical-insulated CAN bus. A laboratory measurement setup has been realized and it has been used to test the prototypes. The obtained experimental results are in very good agreement with the results of numerical simulations and assess the validity of the method. In particular, it has been demonstrated that, even under mismatched conditions, the proposed system allows each PV module of the array to work in its MPP. That is, differently from the case of the string of PV modules, in the case of the string of SCPVMs, the maximum total PV output power is equal to the sum of the maximum powers of the single PV modules.

\section{Conflict of Interests}

The authors declare that there is no conflict of interests regarding the publication of this paper.

\section{References}

[1] N. Femia, G. Petrone, G. Spagnuolo, and M. Vitelli, "Optimization of perturb and observe maximum Power Point Tracking method," IEEE Transactions on Power Electronics, vol. 20, no. 4, pp. 963-973, 2005. 
[2] T. Esram and P. L. Chapman, "Comparison of photovoltaic array maximum Power Point Tracking techniques," IEEE Transactions on Energy Conversion, vol. 22, no. 2, pp. 439-449, 2007.

[3] N. Femia, G. Petrone, G. Spagnuolo, and M. Vitelli, "A new analog MPPT technique: TEODI," Progress in Photovoltaics: Research and Applications, vol. 18, no. 1, pp. 28-41, 2010.

[4] D. P. Hohm and M. E. Ropp, "Comparative study of maximum Power Point Tracking algorithms," Progress in Photovoltaics: Research and Applications, vol. 11, no. 1, pp. 47-62, 2003.

[5] S. B. Kjaer, J. K. Pedersen, and F. Blaabjerg, "A review of singlephase grid-connected inverters for photovoltaic modules," IEEE Transactions on Industry Applications, vol. 41, no. 5, pp. 1292 1306, 2005.

[6] Q. Li and P. Wolfs, "A review of the single phase photovoltaic module integrated converter topologies with three different DC link configurations," IEEE Transactions on Power Electronics, vol. 23, no. 3, pp. 1320-1333, 2008.

[7] R. Alonso, P. Ibáñez, V. Martínez, E. Román, and A. Sanz, "Analysis of performance of new distributed MPPT architectures," in Proceedings of the IEEE International Symposium on Industrial Electronics (ISIE '10), pp. 3450-3455, July 2010.

[8] M. Balato, M. Vitelli, N. Femia, G. Petrone, and G. Spagnuolo, "Factors limiting the efficiency of DMPPT in PV applications," in Proceedings of the 3rd International Conference on Clean Electrical Power: Renewable Energy Resources Impact (ICCEP '11), pp. 604-608, Ischia, Italy, June 2011.

[9] J. Huusari and T. Suntio, "Origin of cross-coupling effects in distributed DC-DC converters in photovoltaic applications," IEEE Transactions on Power Electronics, vol. 28, no. 10, pp. 46254635, 2013.

[10] G. Petrone, C. A. Ramos-Paja, G. Spagnuolo, and M. Vitelli, "Granular control of photovoltaic arrays by means of a multioutput maximum Power Point Tracking algorithm," Progress in Photovoltaics: Research and Applications, vol. 21, no. 5, pp. 918932, 2013.

[11] S. M. MacAlpine, R. W. Erickson, and M. J. Brandemuehl, "Characterization of power optimizer potential to increase energy capture in photovoltaic systems operating under nonuniform conditions," IEEE Transactions on Power Electronics, vol. 28, no. 6, pp. 2936-2945, 2013.

[12] S. Vighetti, J.-P. Ferrieux, and Y. Lembeye, "Optimization and design of a cascaded DC/DC converter devoted to gridconnected photovoltaic systems," IEEE Transactions on Power Electronics, vol. 27, no. 4, pp. 2018-2027, 2012.

[13] S. Poshtkouhi, V. Palaniappan, M. Fard, and O. Trescases, "A general approach for quantifying the benefit of distributed power electronics for fine grained MPPT in photovoltaic applications using 3D modeling," IEEE Transactions on Power Electronics, vol. 99, no. 11, pp. 4656-4666, 2011.

[14] M. S. Agamy, S. Chi, A. Elasser et al., "A high-power-density DC-DC converter for distributed PV architectures," IEEE Journal of Photovoltaics, vol. 3, no. 2, pp. 791-798, 2013.

[15] D. Shmilovitz and Y. Levron, "Distributed maximum Power Point Tracking in photovoltaic systems-emerging architectures and control methods," Automatika: Journal for Control, Measurement, Electronics, Computing and Communications, vol. 53, no. 2, 2012.

[16] A. I. Bratcu, I. Munteanu, S. Bacha, D. Picault, and B. Raison, "Cascaded DCDC converter photovoltaic systems: power optimization issues," IEEE Transactions on Industrial Electronics, vol. 58, no. 2, pp. 403-411, 2011.
[17] C. Olalla, C. Deline, and D. Maksimovic, "Performance of mismatched PV systems with submodule integrated converters," IEEE Journal of Photovoltaics, vol. 4, no. 1, pp. 396-404, 2014.

[18] C. Olalla, M. Rodriguez, D. Clement, and D. Maksimovic, "Architectures and control of submodule integrated DC-DC converters for photovoltaic applications," IEEE Transactions on Power Electronics, vol. 28, no. 6, pp. 2980-2997, 2013.

[19] R. C. N. Pilawa-Podgurski and D. J. Perreault, "Submodule integrated distributed maximum Power Point Tracking for solar photovoltaic applications," IEEE Transactions on Power Electronics, vol. 28, no. 6, pp. 2957-2967, 2013.

[20] G. R. Walker and P. C. Sernia, "Cascaded DC-DC converter connection of photovoltaic modules," IEEE Transactions on Power Electronics, vol. 19, no. 4, pp. 1130-1139, 2004.

[21] N. Femia, G. Lisi, G. Petrone, G. Spagnuolo, and M. Vitelli, "Distributed maximum Power Point Tracking of photovoltaic arrays: novel approach and system analysis," IEEE Transactions on Industrial Electronics, vol. 55, no. 7, pp. 2610-2621, 2008.

[22] C. Deline, B. Marion, J. Granata, and S. Gonzalez, "A performance and economic analysis of distributed power electronics in photovoltaic systems," Technical Report NREL/TP-520050003, 2011.

[23] G. Graditi, G. Adinolfi, and G. M. Tina, "Photovoltaic optimizer boost converters: temperature influence and electro-thermal design," Applied Energy, vol. 115, pp. 140-150, 2014.

[24] G. Graditi, G. Adinolfi, N. Femia, and M. Vitelli, "Comparative analysis of synchronous rectification boost and diode rectification boost converter for DMPPT applications," in Proceedings of the IEEE International Symposium on Industrial Electronics (ISIE '11), pp. 1000-1005, Gdansk, Poland, June 2011.

[25] G. Graditi and G. Adinolfi, "Energy performances and reliability evaluation of an optimized DMPPT boost converter," in Proceedings of the 3rd International Conference on Clean Electrical Power: Renewable Energy Resources Impact (ICCEP '11), pp. 69-72, Ischia, Italy, June 2011.

[26] http://solarmagic.com/en/index.html.

[27] http://www.solaredge.com.

[28] http://www.tigoenergy.com.

[29] http://www.xandex.com.

[30] http://www.st.com.

[31] M. Vitelli, "On the necessity of joint adoption of both distributed maximum Power Point Tracking and central maximum Power Point Tracking in PV systems," Progress in Photovoltaics: Research and Applications, vol. 22, no. 3, pp. 283-299, 2014.

[32] N. Femia, G. Petrone, G. Spagnuolo, and M. Vitelli, Power Electronics and Control Techniques For Maximum Energy Harvesting in Photovoltaic Systems, CRC Press, Taylor \& Francis Group, New York, NY, USA, 2013.

[33] M. Balato, D. Gallo, C. Landi, M. Luiso, and M. Vitelli, "Design and implementation of a hybrid MPPT technique based on the scan of the power versus voltage input characteristic of the inverter," in Proceedings of 19th IMEKO TC 4 Symposium and 17th IWADC Workshop, Advances in Instrumentation and Sensors Interoperability, Barcelona, Spain, July 2013.

[34] M. Balato and M. Vitelli, "A new strategy for the identification of optimal operating points in PV applications with Distributed MPPT,' in Proceedings of the 8th International Conference and Ecological Vehicles and Renewable Energies (EVER '13), pp. 1-7, Monte Carlo, Monaco, March 2013. 
[35] M. Balato and M. Vitelli, "A hybrid MPPT technique based on the fast estimate of the maximum power voltages in PV applications," in Proceedings of the 8th International Conference and Ecological Vehicles and Renewable Energies (EVER '13), pp. 1-6, Monte Carlo, Monaco, March 2013.

[36] S. Liu and R. A. Dougal, "Dynamic multiphysics model for solar array," IEEE Transactions on Energy Conversion, vol. 17, no. 2, pp. 285-294, 2002.

[37] D. T. Lobera and S. Valkealahti, "Dynamic thermal model of solar PV systems under varying climatic conditions," Solar Energy, vol. 93, pp. 183-194, 2013.

[38] R. W. Erikson and D. Maksimovic, Fundamentals of Power Electronics, Kluwer Academic, Norwell, Mass, USA, 2nd edition, 2001.

[39] M. Balato, D. Gallo, C. Landi, M. Luiso, and M. Vitelli, "Simulation and laboratory characterization of a hybrid MPPT technique based on the fast estimate of the maximum power voltages in PV applications," in Proceedings of IEEE International Instrumentation and Measurement Technology Conference (I2MTC '13), Minneapolis, MN, USA, May 2013.

[40] http://tmi.yokogawa.com/products/digital-power-analyzers/ digital-power-analyzers/wt500-power-analyzer/. 

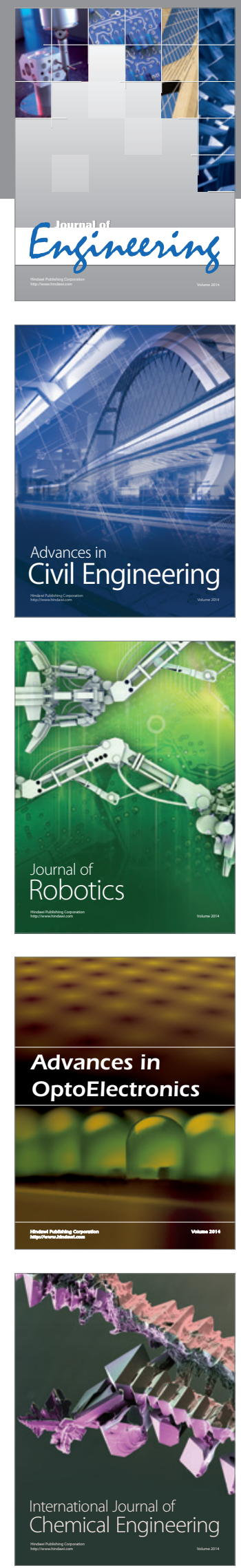

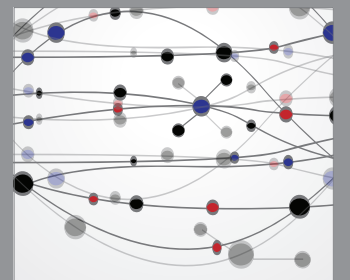

The Scientific World Journal
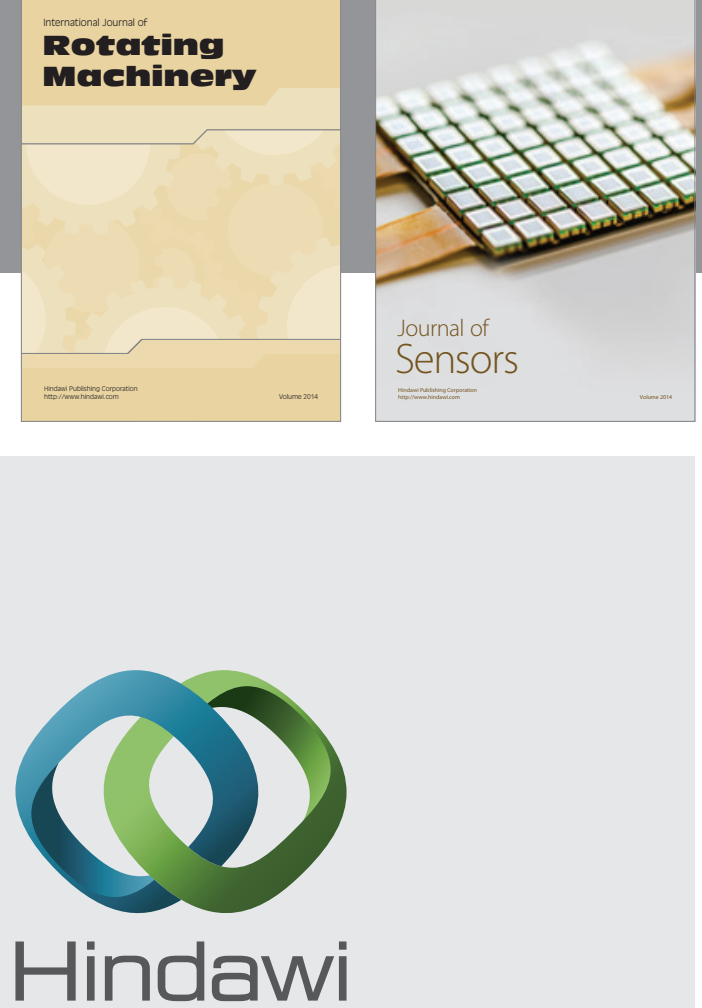

Submit your manuscripts at http://www.hindawi.com
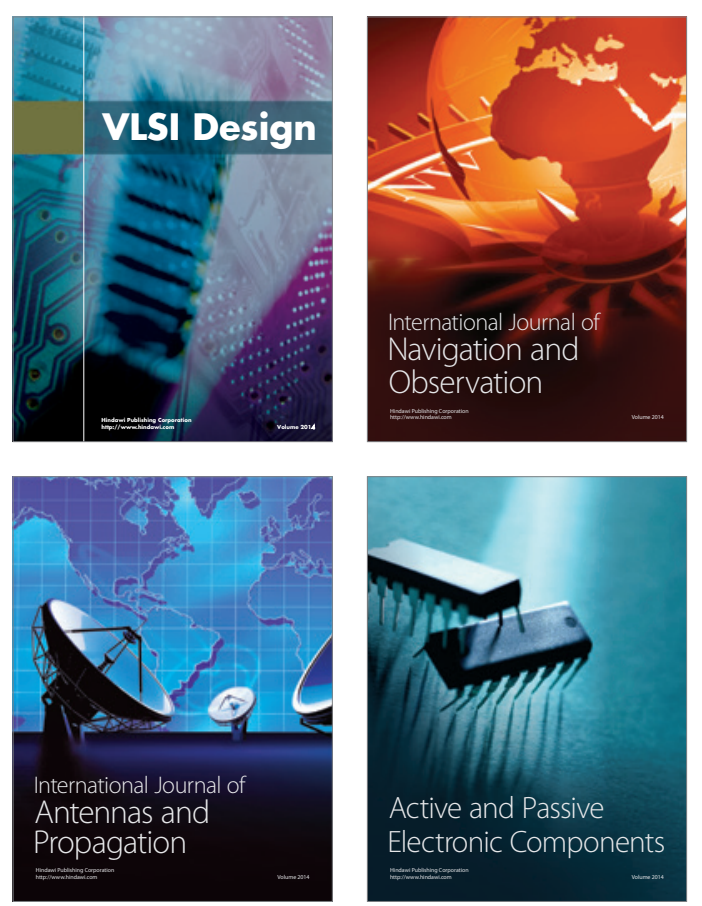
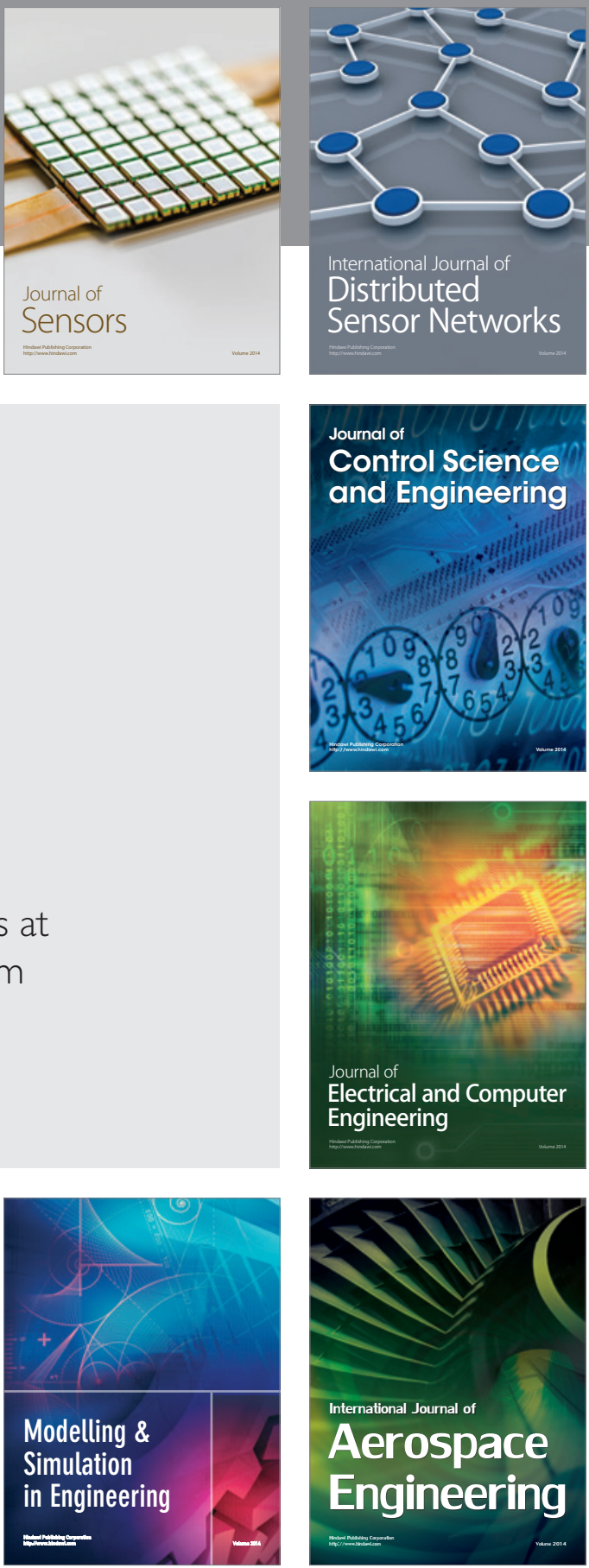

Journal of

Control Science

and Engineering
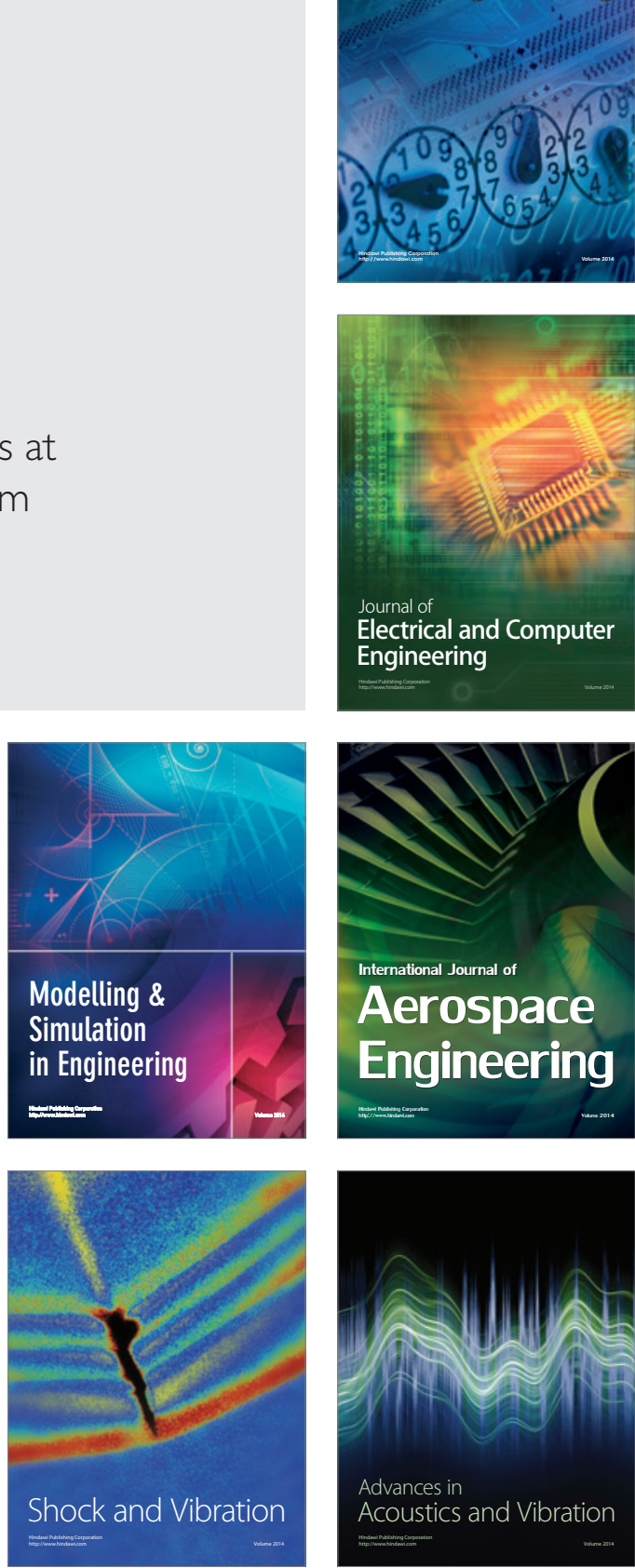